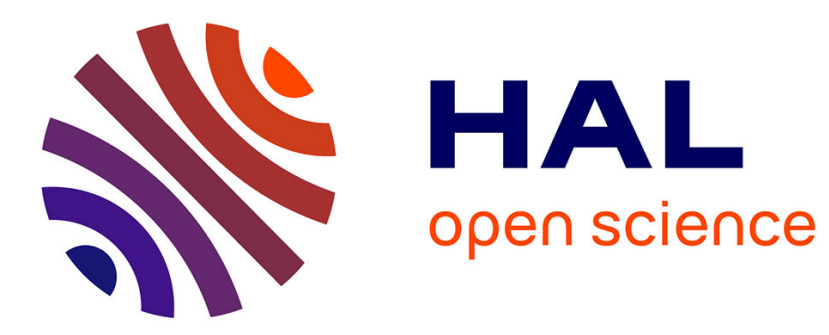

\title{
Vaporization of bulk metals into single-digit nanoparticles by non-thermal plasma filaments in atmospheric pressure dielectric barrier discharges
}

\author{
J.-P. Borra, N. Jidenko, J. Hou, A. Weber
}

\section{- To cite this version:}

J.-P. Borra, N. Jidenko, J. Hou, A. Weber. Vaporization of bulk metals into single-digit nanoparticles by non-thermal plasma filaments in atmospheric pressure dielectric barrier discharges. Journal of Aerosol Science, 2015, 79, pp.109-125. 10.1016/j.jaerosci.2014.09.002 . hal-03265739

\author{
HAL Id: hal-03265739 \\ https://hal.science/hal-03265739
}

Submitted on 21 Jun 2021

HAL is a multi-disciplinary open access archive for the deposit and dissemination of scientific research documents, whether they are published or not. The documents may come from teaching and research institutions in France or abroad, or from public or private research centers.
L'archive ouverte pluridisciplinaire HAL, est destinée au dépôt et à la diffusion de documents scientifiques de niveau recherche, publiés ou non, émanant des établissements d'enseignement et de recherche français ou étrangers, des laboratoires publics ou privés. 


\title{
VAPORIZATION OF BULK METALS INTO SINGLE-DIGIT NANOPARTICLES BY NON-THERMAL PLASMA FILAMENTS IN ATMOSPHERIC PRESSURE DIELECTRIC BARRIER DISCHARGES
}

\author{
J.-P. Borra ${ }^{\mathrm{a}}$, N. Jidenko ${ }^{\mathrm{a}}$, J. Hou ${ }^{\mathrm{b}}$, A. Weber ${ }^{\mathrm{b}}$
}

a) Laboratoire de Physique des Gaz et Plasmas CNRS-Univ. Paris-Sud, Orsay, F-9140 Supélec,

3 Rue Joliot Curie, Gif-sur-Yvette, F-91192, France, 00.33.1.69.15.36.74, jean-pascal.borra@u-psud.fr b) Institute of Particle Technology, Technical University of Clausthal, Clausthal-Zellerfeld, Germany

\begin{abstract}
A compact, inexpensive and simple Dielectric Barrier Discharge (DBD) design is presented with related electro-thermal properties for the production of metal nanoparticles. Nanoparticle formation and growth mechanisms are depicted from size distributions and chemical analyses of particles collected just after the $70 \mathrm{kHz}$ DBD in Nitrogen. At first, it is confirmed that the initial local vapor flux is produced from the spots of interaction between plasma filaments and different metal electrodes ( $\mathrm{Au}, \mathrm{Ag}$, and $\mathrm{Cu}$ ). Amorphous and crystalline pure metal primary nanoparticles with diameters below $5 \mathrm{~nm}$ are then produced by physical nucleation in expanding vapors jets. Finally, some small agglomerates with diameters still below $5 \mathrm{~nm}$ are also formed by ballistic agglomeration of a fraction of these primary particles. This happens at the end of the vapor jet expansion, as well as after the production during the transit between subsequent filaments in the DBD. The first local agglomeration step can be limited at reduced energy per filament by lowering the initial vapor flux in smaller gaps, while the second growth step depends on the transit time in the DBD. Hence, such "low" energy plasma filaments (up to a few tens of $\mu \mathrm{J}$ ) lower the initial vapor flux to control the agglomeration. DBD were thus successfully tested for the production of tailored nanoparticles with tunable size, controlled morphology of spherical agglomerates and the same composition as the metal electrode. The production per unit energy $\left(\mathrm{mol} . \mathrm{J}^{-1}\right)$ is related to both plasma and material properties. Besides, neglecting vapor and nanoparticles losses, the mass production rate $\left(\mathrm{g} \mathrm{s}^{-1}\right)$ depends on the input power related to the product of the energy controlling the production per filament times the number of filaments per second, for any given material. This non-thermal plasma process presents great potentialities for nano-technologies since it is performed at atmospheric pressure and can be used to reach size-dependent properties of nano-materials, without any gaseous precursor or solvent.
\end{abstract}

Keywords:

Dielectric Barrier Discharge; plasma; nanoparticle; production; mechanism; nucleation; process

\section{Introduction}

Size-dependent properties are reported for particles smaller than $50 \mathrm{~nm}$ (Kodas, 1999, Schmid 2011). Hence, the ideal nano-material production process should control the size, the composition and the structure of primary nanoparticles as well as the coagulation enlarging the size distribution.

Nano-particles suspended in gases are formed by evaporation of liquid droplets or by condensation of vapors. In both cases, homogeneous nucleation occurs when the saturation concentration is overcome (saturation vapor pressure in gases and solute concentration for crystallization in liquids). Nucleation here refers to the bottom-up gas phase process producing nanoparticles from condensable vapors.

In reactive nucleation processes, condensable species are produced by chemical reactions between gaseous precursors and excited species from flames, plasmas or lasers. High production rates are reached but purity of the so-produced nanoparticles still is a critical limit that deserves to be addressed (e.g. in Pratsinis et al. 2008 for flames, in Vollath and Szabó 2006 and in Kortschagen's chapter from Samukawa 2012 for Low pressure plasmas, as well as for ambient pressure processes by plasmas in Belmonte et al. 2011, and in Massines et al. 2012, or by lasers in Sublemontier 2011).

To reach pure nanoparticle production, physical nucleation by cooling hot vapors evaporated from solid materials has been first developed for low pressure coating process. Solid vaporization is also performed at ambient pressure to produce particles with the same composition than the solid target. Continuous thermal arc or short successive and focused energy deposits on the material by lasers and sparks (first reported by Altgeld 1980) are used. The interaction surface is referred to spot with related 
power densities above $10^{10} \mathrm{~W} \cdot \mathrm{m}^{-2}$ and energy densities up to $10^{6} \mathrm{~J} \cdot \mathrm{m}^{-2}$ above the threshold fluency of $10^{3} \mathrm{~J}_{\mathrm{m}} \mathrm{m}^{-2}$ for metal vaporization (e.g. for lasers in Gamali 2011). Then, high nucleation rates lead to concentrations of primary nanoparticles above $10^{10} \mathrm{~cm}^{-3}$, favorable to fast coagulation. The so-produced aerosol presents mean diameters up to a few hundred nm (Kodas and Hampden-Smith, 1999, Horvath and Gangl, 2003, Byeon et al. 2008, Buesser B et al. 2009 and Bau et al. 2010). Agglomeration has been limited in sparks by dilution (Feng et al. 2013), by quenching in pin-to-hole configurations (Han et al. 2012), and by unipolar charging (Park et al. 2014). Sparks in liquids also leads to a fraction of unagglomerated nanoparticles embedded in carbon (Hamdam et al. 2013). Besides, less energetic nonthermal plasma filaments $(0.1-10 \mathrm{~mJ}$ prevented sparks and 10-100 $\mu \mathrm{J}$ streamers) still lead to final size distributions with count mean diameters from 10 to $100 \mathrm{~nm}$, arising from coagulation of primary nanoparticles (Borra et al. 2008, 2009, 2011).

The paper describes another method to produce even smaller primary metal particles from 1 to $5 \mathrm{~nm}$ and to control the agglomeration with final diameters still below $5 \mathrm{~nm}$. To do so, less energetic plasma filaments (from 1 to tens of $\mu \mathrm{J}$ ) are used to reduce the initial vapor flux. To compensate this low local vapor production per filament, filaments are repeated more than $10^{6} \mathrm{~s}^{-1}$ for ms transit times in lab-scale DBD at $70 \mathrm{kHz}$.

In such streamer-like discharge filaments, the transition to thermal spark must be avoided by limiting the reduced electric field ( $E / N$ with $N$ the gas density) and the related current. In that respect, DBD have been developed using an $\mathrm{AC}$ voltage with at least one dielectric material (barrier) between the electrodes. The electric field in the gap depends on the applied voltage and on charges first migrating in the gap and then deposited on dielectric surface during the development of filaments (Gibalov and Pietsch, 2000, and Eliasson and Kogelschatz 1991). Surface polarization first amplifies the electric field to trigger economic plasmas filament development and then hinders the transition from non-thermal streamer to thermal spark. In air and nitrogen at atmospheric pressure, thin and transient discharge filaments, also called micro-discharges develop with diameters of 10-100 $\mu \mathrm{m}$ and durations of 20-500 ns. Here, the expression "discharge filament" includes all phases from Townsend pre-breakdown avalanches to streamer development towards the cathode, surface discharges and quenching.

A simple DBD design is presented with electro-thermal properties for the production of nanoparticles from the surface of solids. Nanoparticle formation and growth mechanisms are discussed from Selected Area Electron Diffraction (SAED) and Transmission Electron Microscopy (TEM) analysis.

Finally, production per unit energy $\left(\mathrm{mol} \mathrm{J}^{-1}\right)$, the final particle size and the mass production rate $\left(\mathrm{g} \mathrm{s}^{-1}\right)$ of nanoparticles are related to plasma parameters, to properties of materials for gold, silver and copper as well as to transit times in the plasma.

\section{General set-up and Aerosol measurements}

The experimental set-up is presented in Figure 1. Plasma reactors are fed with $\mathrm{N}_{2}$ at STP. Transit times in the gap lie from 1 to 20 milliseconds in lab-scale DBD.

Reactive nucleation may arise from gaseous impurities converted into condensable species by reactive non-thermal plasmas. It can be suppressed using filtered dry inert or non-reactive gases. Then whatever 99.99 to $99.999 \%$ purities used, similar aerosol measurements are performed and detected aerosol can only be produced by physical nucleation of vapors emitted from spots of plasma filaments.

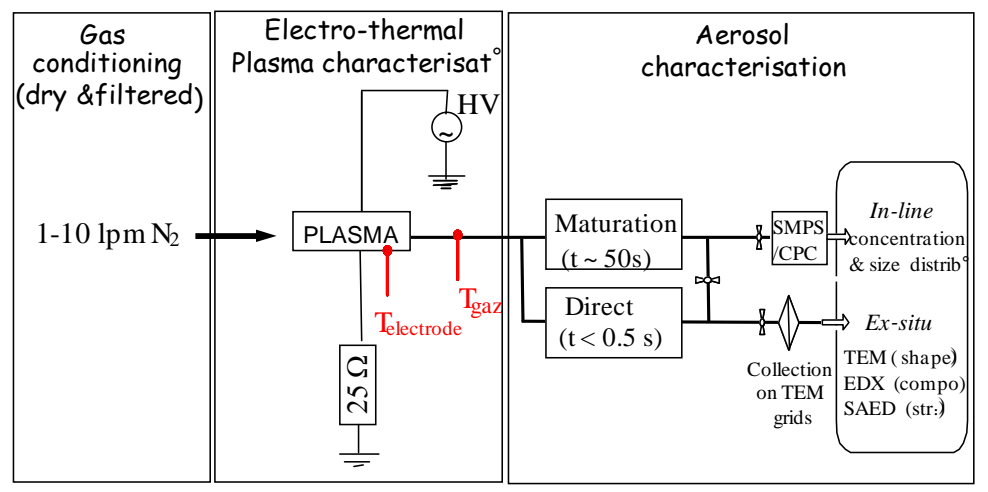

Figure 1: General set-up for aerosol production studies versus electro-thermal properties of plasma filaments 


\subsection{Electro-thermal characterization of DBD}

Figure 2 shows the plane-to-plane DBD reactor design that has been used with millimeter gaps. This lab-scaleDBD is made of metal electrodes ( $\mathrm{Ag}, \mathrm{Au}$ or $\mathrm{Cu}$ with diameters of 4,8 and $8 \mathrm{~mm}$ respectively), facing the dielectric material $\left(\mathrm{Al}_{2} \mathrm{O}_{3}\right)$ polarized at $70 \mathrm{kHz}$ by a $2 \times 3 \mathrm{~cm}^{2}$ electrode. This asymetric planar DBD has been used for electrical characterisation. Indeed, the accurate electrical characterisation of current pulses related to properties of discharge filaments requires an electrode area smaller than $1 \mathrm{~cm}^{2}$ to prevent from too numerous pulses occurring at the same time on larger electrodes (Jidenko et al., 2006). Different gap lengths from 1 to $3.65 \mathrm{~mm}$ were fed with 1 to $10 \mathrm{lpm} \mathrm{N}_{2}$ to keep the gas velocity constant at $0.5 \mathrm{~m} \mathrm{~s}^{-1}$, for all the results presented here.

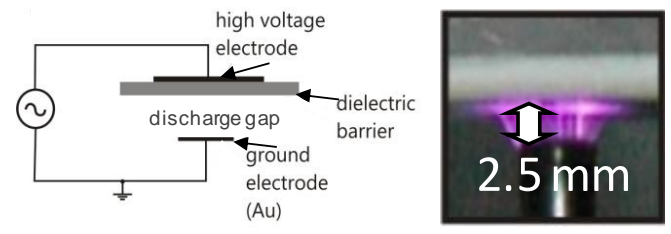

Figure 2: Set-up and picture of discharge filaments in a $2.5 \mathrm{~mm}$ gap at $U_{p p}=13 \mathrm{kV}$ in the lab-scale DBD

The experimental setup used to perform voltage and current measurements as well as calculations of the discharge power and the number of filaments during the transit time, are detailed in appendix 1.

For each operating condition, applied voltage, input power and individual current pulse characteristics such as the maximum current pulse, the duration, the charge per pulse have been measured in each half-period (e.g. for a $1 \mathrm{~mm}$ gap in Nitrogen, $I_{0} \sim 20 \mathrm{~mA}, \Delta t \sim 100 \mathrm{~ns}, Q$ around nC and $\mathrm{E}_{\text {/pulse }}$ from a few to tens of $\mu \mathrm{J}$ ). This allows one to calculate the number of pulses per square centimeter during a voltage period $\left(N_{\text {pulser }}\right.$ of a few tens per square centimeter, for a $1 \mathrm{~mm}$ gap) and the energy per pulse (cf. appendix 1 and $\$-3.1$ results).

The lab-scale DBD has been extensively studied in terms of electro-thermal properties, detailed in Jidenko 2006 and 2010. The temperatures of the electrode and of the gas have been measured with thermocouples.

\subsection{Aerosol measurements}

To evaluate the production of particles by DBD, losses and detection efficiencies versus the diameter of particles have to be taken into account to correct the post-discharge concentration measurements. To do so, all measurements presented here have been obtained at the quasi-stationary thermal equilibrium, i.e. 20 to $30 \mathrm{~min}$ after the lightning of the discharge, as depicted in the results (cf. §3.1).

Particle size distributions and concentration: The aerosol size distribution, modal diameters and geometric standard deviations are measured by two methods: (i) just at the exit of the lab-scale DBD for particles with modal diameters smaller than $5 \mathrm{~nm}$ collected on TEM grids for image analysis of at least 500 particles for all size distribution presented in section 3 ; (ii) by in-line Scanning Mobility Particle Sizer (radial nano Differential Mobility Analyzer from Clausthal University) after coagulation for $60 \mathrm{~s}$ downstream the lab-scale DBD, as depicted in Figure 3.

Due to the small size of the primary nucleated particles as well as of agglomerates, respectively with count mean diameters below $3 \mathrm{~nm}$ and up to 5, only a fraction of particles is detected in the Condensation Particle Counter (Grimm 5.403), as depicted on Figure 3. Thus, to perform mass production rate evaluation discussed in section 3.4.5.1, the agglomerate number concentration $\left(N_{\text {agglom. }}\right)$ was derived from the SMPS measurements or measured directly with the CPC for particles larger than $3 \mathrm{~nm}$, formed in the post-discharge agglomeration chamber for $60 \mathrm{~s}$. 


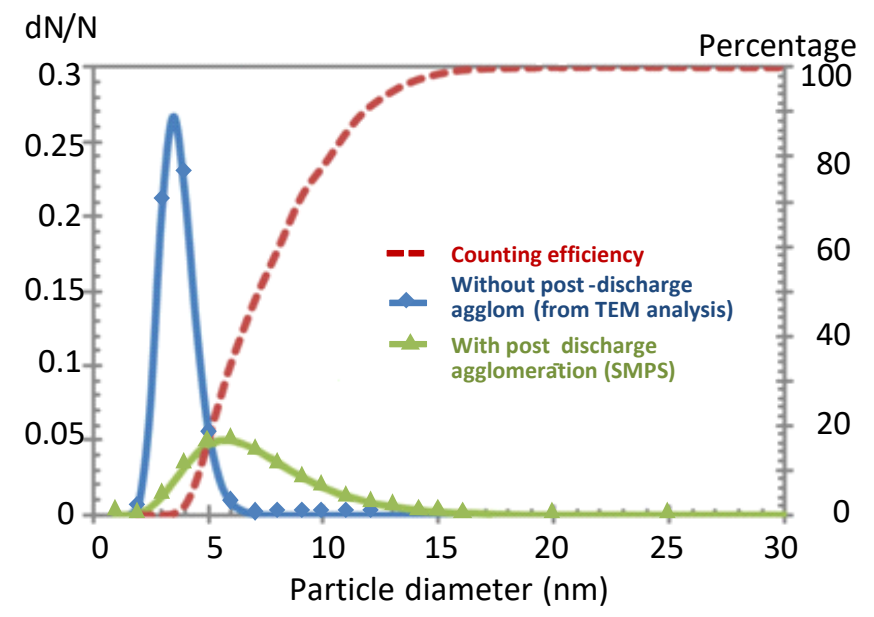

Figure 3: Counting efficiency of CPC and size distributions of primary particles (TEM) and of agglomerated particles produced by $\mathrm{Cu}-\mathrm{DBD}\left(U_{p p}=13 \mathrm{kV}, g=2.45 \mathrm{~mm}, Q_{N 2}=5 \mathrm{lpm}\right)$

Finally, calculations detailed in appendix 2 have shown that post-DBD losses by thermophoresis and electrostatic repulsion can be neglected while diffusion losses in the DBD as well as in post-DBD have to be taken into consideration for particles smaller than $5 \mathrm{~nm}$.

Collection for Transmission Electron Microscope (TEM) analysis: The aerosol has been sampled at $0.3 \mathrm{lpm}$ through a carbon coated TEM grid (lacey type) downstream the plasma aerosol generator. The time of collection depends on the aerosol concentration (e.g. 15 minutes for particle number concentration of $10^{7} \mathrm{~cm}^{-3}$ ). The additional characteristics, such as the size and shape of primary nanoparticles and of agglomerates were investigated with a TEM. Then, the particle size distributions were determined from the TEM images including at least 500 particles. The count median diameter $\left(\mathrm{d}_{\mathrm{p}}\right)$ and the geometrical standard deviation $\left(\sigma_{g}\right)$ were defined by fitting the size distribution with a log-normal distribution.

Atomic composition and crystalline structure were defined from Selected Area Electron Diffraction (SAED) in the same TEM (JEOL 2100) from diffraction pattern. From the electron diffraction pattern the crystal structure of the sample can be determined if the lattice constants are known. Besides, additional EDX analyses have also been performed on collected nano-particles. 


\section{Results and discussion}

\subsection{Electro-thermal characterization and properties of plasma filament in DBD}

Figure 4 depicts the spatial development of filaments integrated over a few periods for a ms in our labscale DBD. Brighter and longer filaments develop at the edges of the metal electrode than from the central part. This was expected from the geometrical field reinforcement on the edges. Besides, filaments are spread on more spots on the dielectric side than on the metal side. This is due to charge deposition by the filament and related surface polarization of the dielectric material. This prevents from the lightning of subsequent filaments at the same place on the dielectric side during the same half period. On the metal side, the electric field is not retro-controlled by surface polarization and filaments can develop from the same spot on the edges of the metal electrode, as depicted in Figure 4b.
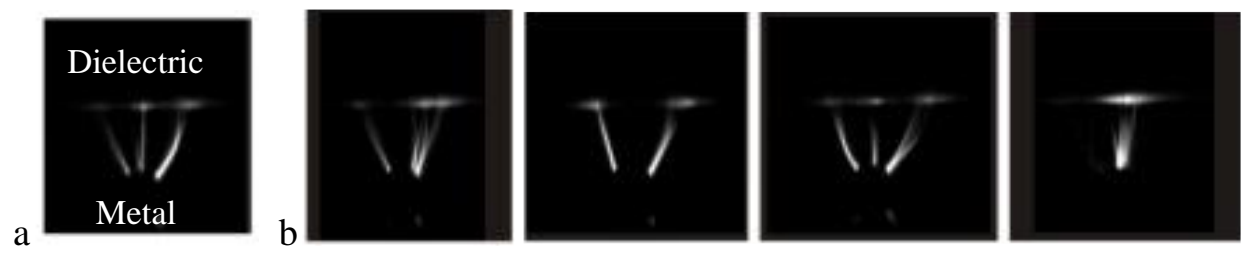

Figure 4: photos of filaments during $1.1 \mathrm{~ms}$ aperture in the DBD at $13 \mathrm{kV}, 70 \mathrm{kHz}, g=2.45 \mathrm{~mm}, V_{N 2}=0.5 \mathrm{~m} \mathrm{~s}^{-1}$ with a) less luminous filaments in the central volume of the gap in lower electric field than on the edges and $b$ ) more spots on the dielectric polarized material than on the metal

The measured current is depicted in Figure 5a. All results presented here have been obtained after at least $30 \mathrm{~min}$ after the lightning of the discharge. Indeed, the surface and related gas temperatures evolve as presented in Figure $5 \mathrm{~b}$ for a mean electrode temperature from 20 to $130{ }^{\circ} \mathrm{C}$.

a)

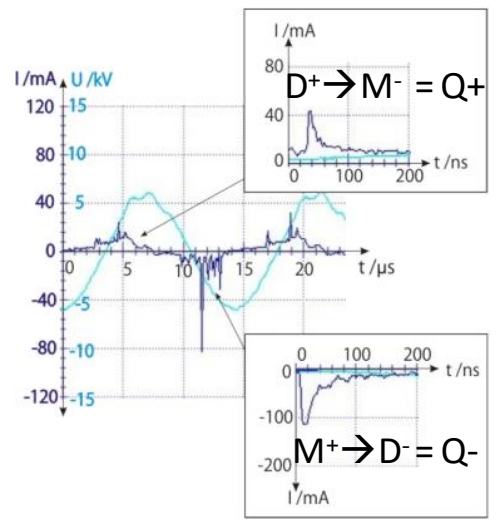

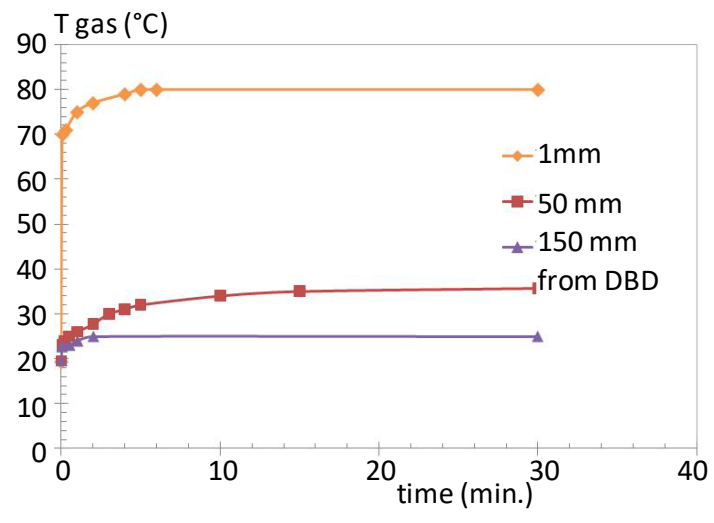

b)

Figure 5 : a) Instantaneous discharge current and applied voltage and zoom on current pulses ; b) Evolution of gas temperatures in post-DBD at $70 \mathrm{kHz}$ and $12 \mathrm{kV}$, fed with $5 \mathrm{lpm}$ nitrogen.

During the positive half-period, the discharge filaments $\left(\mathrm{D}^{+} \rightarrow \mathrm{M}^{-}\right)$cross the gap towards the metal electrode with charge and energy per filament hereafter referred as $Q_{+}(\mathrm{nC})$ and $E_{+}(\mu \mathrm{J})$. Reversely, during the following negative half-period, filaments impact the dielectric material, which is now acting as a cathode $\left(\mathrm{M}^{+} \rightarrow \mathrm{D}^{-}\right)$with charge and energy per filament, referred as Q- and E.

Current measurement: the measured current is the sum of two discharge current components (conduction current due to the collection of charges on the metal electrode and displacement current of charges in the gas), as well as a third capacitive current component, shifted of $T / 4$ from the voltage.

Once the capacitive current suppressed by a numerical method detailed in Petit et al. 2002, the measured current is quasi-exclusively composed of current pulses related to discharges filaments. Indeed, the pseudo-continuous current related to ion drift is not measurable. Besides, in nitrogen, electron attachment can be neglected. Then, the current is only related to electrons and positive much less mobile nitrogen ions. The measured current thus mainly corresponds to the conduction current related to the electron flux integrated on the surface of spots.

One important feature of these plasma filaments is the quasi-constant charge and related energy per filament in each polarity, whatever the applied voltage is for a $2.5 \mathrm{~mm}$ gap at $70 \mathrm{kHz}$ (see Figure $6 \mathrm{a}$ ).

The linear evolution of power with the applied voltage is depicted in Figure 6b. Indeed, the voltage 
controls the number of filament per half period at quasi-constant energy per filament in each polarity. In the order of millions of filaments are so-produced per second in such lab-scale DBD with sub-square centimeter electrode surface. The voltage controls the input power and the directly related temperatures of surfaces and of gas, as already reported in Jidenko et al. 2010 (cf. Figure 5b).

Moreover, the charge per filament is proportional to the gap $(\mathrm{g}, \mathrm{mm})$ as depicted in Figure $6 \mathrm{c}$ while the energy evolves faster up to a few tens $\mu \mathrm{J}$ with the gap length, as depicted in Figure $6 \mathrm{~d}$.
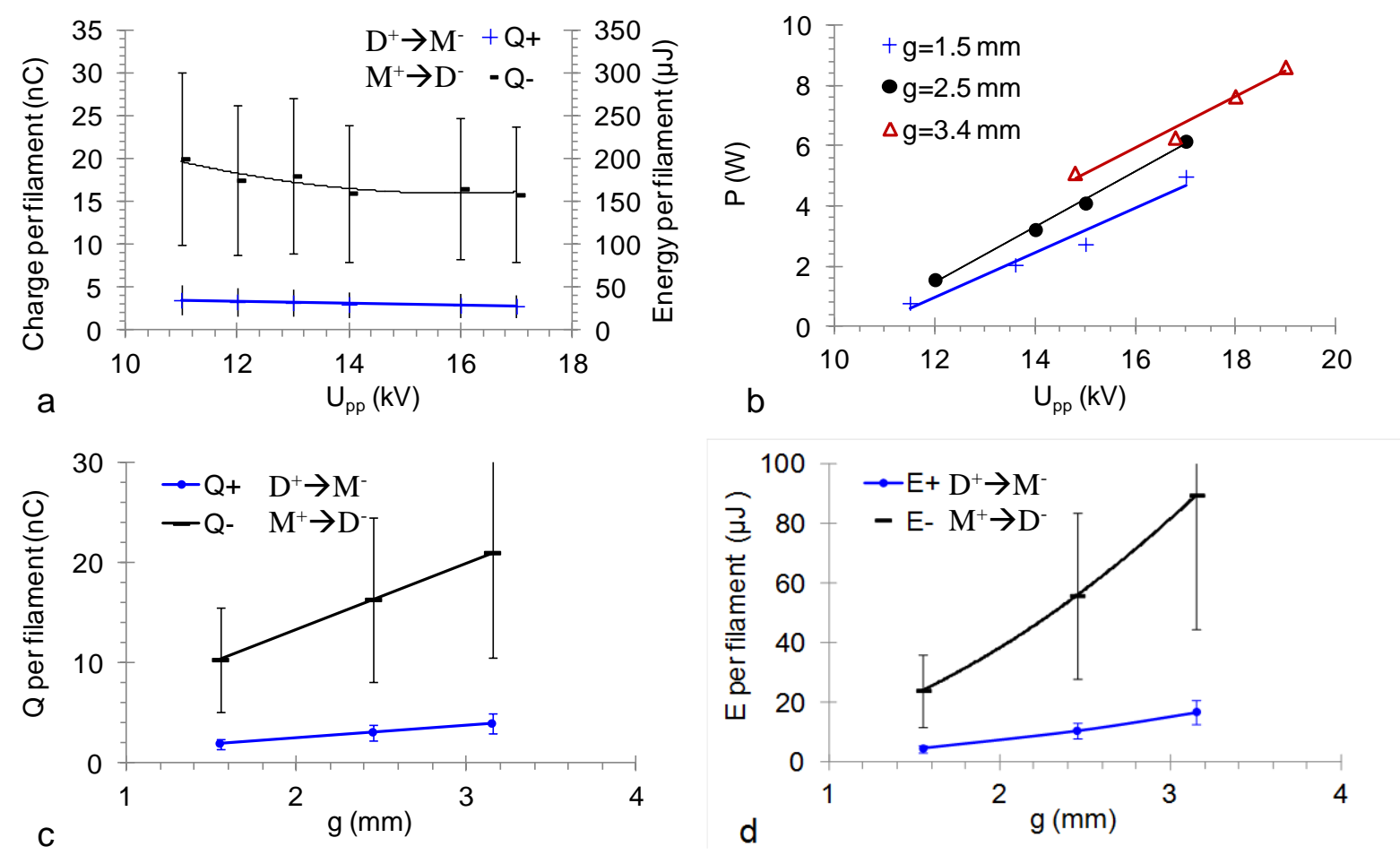

Figure 6 : Influence of the applied voltage (a) on the charge per filament and (b) on the discharge power in AuDBD at $2.45 \mathrm{~mm}$; Influence of the gap $(g$ in $\mathrm{mm})(\mathrm{c})$ on the charge and (d) on the energy per filament at $15 \mathrm{kV}$.

\section{Difference between metal-directed and dielectric-directed streamer-like discharge filaments}

Both the charge and the energy of the metal-directed filaments are smaller than for dielectric-directed filament, as depicted in Figure 6 and already observed by Murata et al. 1995 and Falkenstein and Coogan 1997. This has been attributed to the dynamic of collection of charges on anodic and cathodic surfaces. The electric field in the gap is mainly controlled by the surface polarization. Hence, the anodic dielectric surface neutralization by electron during the positive $1 / 2 T\left(Q_{+}\right)$is faster than by positive ions during the negative one $(Q$.). This can account for a faster field reduction leading to smaller charge and energy per pulse during the positive $1 / 2 \mathrm{~T}$ than during the negative one.

The polarization of the dielectric surface can also accounts for the higher dispersion of $Q$. related to dielectric-directed filaments than for $Q_{+}$related to metal-directed filament (see Figure 6a and c). At first, lower mobilities of positive ions than of electrons induces a faster surface extension of deposited electrons than of positive ions. Then, the retro-controlled total electric field is lowered for longer period and to a smaller value, just above the spots polarized by positive ions than by electron. Once polarized by positive ions of the first filament in the central part, subsequent filament during the same $1 / 2$ period are repelled away on longer path to reach the less polarized periphery of the dielectric surface. Since the charge per pulse is proportional to the discharge length, shorter distances and homogeneous field in the central part of the electrode lead to smaller charge per filament in the central part than for longer filaments on the edges of the metal pin (field reinforcement).

Similar observations have been made for different gap lengths, as presented in Figure $6 \mathrm{~b}$ as well as for different electrode material including gold, copper and silver.

The charge per filament and the number of filaments per unit surface and per period are quasiconstant from 1 to $100 \mathrm{kHz}$, in a DBD for any given voltage. Hence, in such DBD reactor, the number of filaments per second thus increases linearly with frequency and with the number of filaments per period that can be tuned with the voltage, the gap length and the surface of the electrodes. 


\subsection{Physical Nucleation and agglomeration in expanding vapor jets}

\subsubsection{Micro-discharge $\rightarrow$ Surface vaporization and nucleation in expanding vapor jet}

In lab-scale DBD, with transit times in the gap of a few milliseconds, the mean diameter of the produced particles are systematically smaller than $5 \mathrm{~nm}$. A TEM image of gold particles produced by the Au-DBD is shown in Figure 7, with the corresponding size distribution.
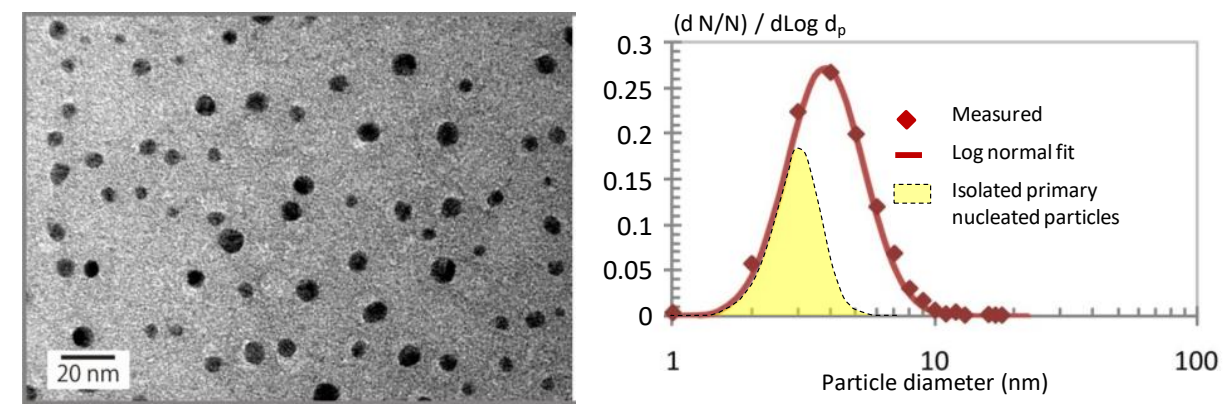

Figure 7: Overview of gold particles and corresponding size distribution $\left(U_{p p}=13 \mathrm{kV}, g=2.5 \mathrm{~mm}\right.$, transit time $=4 \mathrm{~ms}$ in Au-DBD with 1506 particles)

This confirms that we are dealing with nucleation, implying the production of saturated vapors. The size distributions presented in this paper integrate both populations of primary nucleated particles $(<5 \mathrm{~nm})$ and of agglomerates (e.g. in Figure 7), distinguished from TEM pictures in Figure 8a.

Primary nucleated particles $(<\mathbf{5} \mathbf{~ m m})$ : All individual particles sized from TEM observation lie in the range from 0.8 to $5 \mathrm{~nm}$. Indeed, as depicted in Figure 7. The size distribution of primary nucleated particle is not a lognormal one since the smallest primary particle may not be visible due to enhanced losses by diffusion for smaller sizes. In that case, slightly more than half of the nanoparticles collected in post-DBD are unagglomerated isolated primary nucleated particles.

(a)

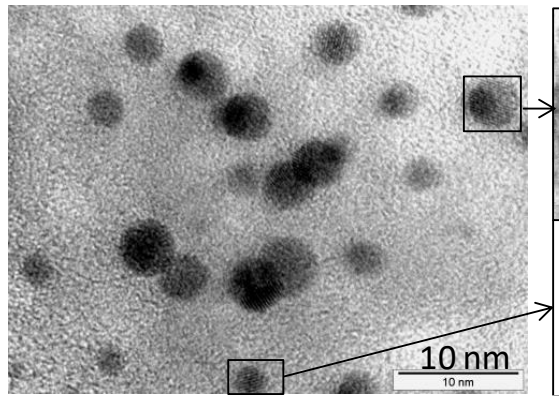

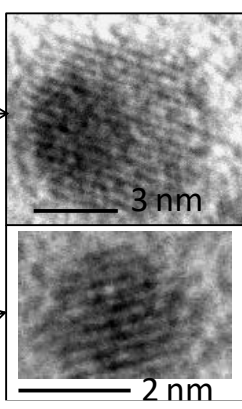

(b)

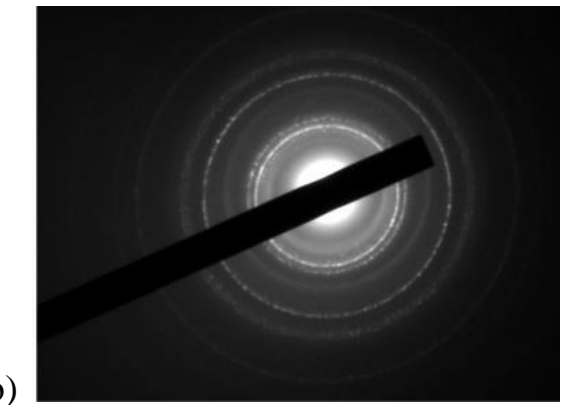

Figure 8: TEM micrograph of gold particles and corresponding SAED figure of Au fcc crystalline structure $\left(U_{p p}=11 \mathrm{kV}, g=1.65 \mathrm{~mm}, \mathrm{Au}-\mathrm{DBD}\right)$

Crystalline structure of nanoparticles: Parallel lattice planes are visible on crystalline nanoparticles as depicted in Figure 8a. From the concentric circles derived from SAED on crystalline nanoparticles, shown in Figure 8b, the lattice constants with the Miller indices can be determined. Particles show lattice constants of $2.355 \AA$ corresponding to the (111) reflection plane and $2.039 \AA$ for the (002) reflection plane of the lattice face-centered cubic (fcc) crystal structure of gold.

From all primary nucleated particles, about $20-30 \%$ is mono-crystalline versus an amorphous fraction of about $70-80 \%$. This confirms that the nucleated particles are formed in different thermal conditions, as expected in expanding nucleation fronts depicted by Wang 2010 a and b, Autrique 2013 and Farid 2014 for lasers and by Smirnov 1993, Itina and Voloshko 2013 for sparks.

Composition of nanoparticles: $\mathrm{EDX}$ analyses show only a few $\mathrm{Al}_{2} \mathrm{O}_{3}$ nanoparticles on the grid. The large excess of metal nanoparticles was expected since the enthalpy of melting required prior to vaporization is smaller and the saturation vapor pressures are higher for metals than for $\mathrm{Al}_{2} \mathrm{O}_{3}$.

Hence, the initial vapor flux is produced by local surface vaporization from the spots of interaction between plasma filaments and surfaces. Pure crystalline and amorphous nanoparticles $(<5 \mathrm{~nm})$ with the same composition than the metal electrode are so-formed by physical homogeneous nucleation in the mobile front of expanding vapor jets. 


\subsubsection{Growth of primary nucleated particles in the expanding vapor jet $\rightarrow$ Agglomerates}

Rather spherical agglomerates with sizes from 3 to $10 \mathrm{~nm}$ made of primary nucleated particles (from 2 to $5 \mathrm{~nm}$ ) are also observed in Figures 7 and 8 a. To check whether these agglomerates were produced by local agglomeration in the vapor jet and/or during the transit between the subsequent filaments in the $\mathrm{DBD}$, the following plasma and material parameters have been varied.

\subsubsection{Energy per filament}

Figure $9 \mathrm{~b}$ shows the particle size distributions produced by Au-DBD for different gap lengths at constant gas velocities. The number of filaments during the transit in the DBD was also kept constant by lowering the applied voltages in smaller gaps, as depicted in Table 1.

(a)
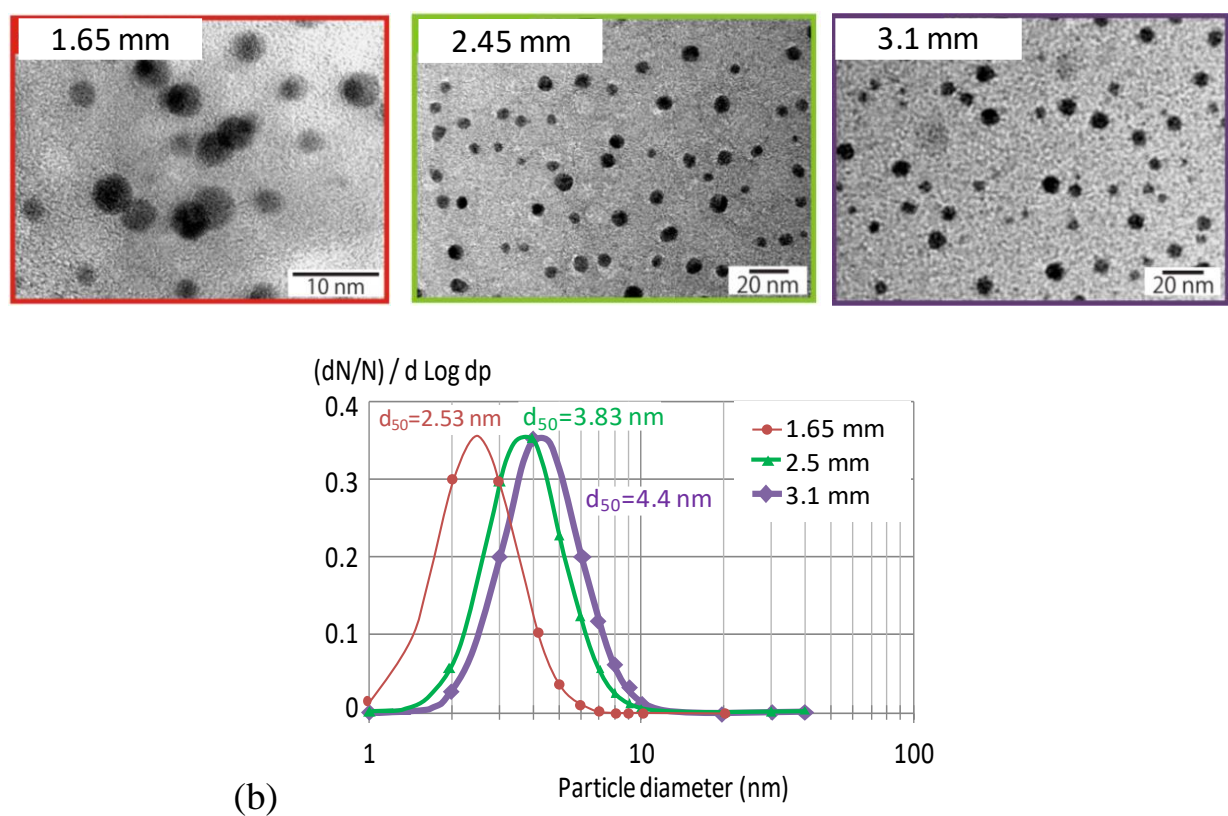

Figure 9: (a) TEM pictures of gold nanoparticles produced in Au-DBD and (b) related size distribution, versus gap lengths ( $g$ in $\mathrm{mm})$

Table 1: Results from the analysis of TEM images in Au-DBD for different gap lengths

\begin{tabular}{llll} 
Gap length $(\boldsymbol{g}$ in $\mathbf{~ m m})$ & $\mathbf{1 . 6 5}$ & $\mathbf{2 . 4 5}$ & $\mathbf{3 . 1}$ \\
\hline Applied voltage $\left(V_{p p}\right.$ in $\left.\mathrm{kV}\right)$ for similar number of filaments during the transit in DBD & 11 & 13 & 15 \\
\hline Count mean diameter $d_{50}(\mathrm{~nm})$ of primary particles & 2.53 & 3.83 & 4.4 \\
\hline Geom. Standard dev. $\left(\sigma_{g}\right)$ & 1.45 & 1.4 & 1.4 \\
\hline Number of particles included for size dist. from TEM pictures & 528 & 1506 & 870
\end{tabular}

From Figure 9a, it can be seen that the sizes of both primary nucleated particles $(<5 \mathrm{~nm})$ and the resulting aggregates $(<10 \mathrm{~nm})$ increase with gap length and corresponding energy per filament. The count mean diameter of related size distribution integrating both populations, as well as the fraction of agglomerated particles increase with increasing gap (cf. Figure 9 and Table 1).

This is typical of nucleation at higher vapor flux and was expected with more energetic filaments in larger gaps. Indeed, the resulting higher saturation leads to smaller critical diameters and subsequent longer nucleation, with related larger primary particles. Moreover, the nucleation frequency also increases with the local saturation. Then, higher concentrations of primary particles are produced by each filament, leading to faster coagulation and to larger agglomerates with more energetic filaments.

\subsubsection{Electrode material}

Nanoparticles have been produced by DBD with gold, silver and copper electrodes at constant energy per filament and number of filaments during the transit in the DBD. Similar isolated primary nucleated nanoparticles and related agglomerates are observed. Similar size distributions with modal diameters below $5 \mathrm{~nm}$ are produced, whatever the electrode material is, as depicted in Figure 10 and detailed in Table2. 


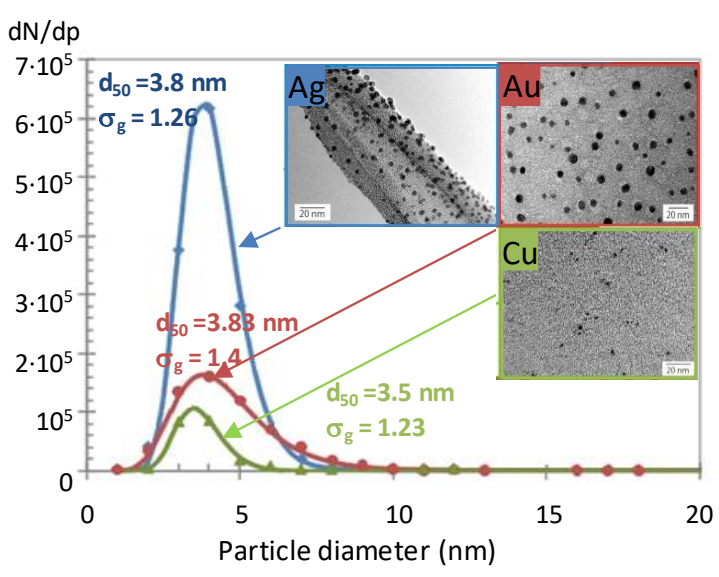

\begin{tabular}{|l|l|l|l|}
\hline Material & $\mathbf{A g}$ & $\mathbf{A u}$ & $\mathbf{C u}$ \\
\hline Count mean diameter $(\mathrm{nm})$ & 3.8 & 3.83 & 3.5 \\
\hline geom. standard $\left(\sigma_{g}\right)$ & 1.26 & 1.4 & 1.23 \\
\hline flow rate $\rightarrow$ velocity & \multicolumn{3}{|c|}{$5 \mathrm{lpm} \leftarrow \rightarrow 0.5 \mathrm{~m} \mathrm{~s}^{-1}$} \\
\hline DBD transit time & $16 \mathrm{~ms}$ & \multicolumn{3}{|c|}{$8 \mathrm{~ms}$} & $16 \mathrm{~ms}$ \\
\hline post-DBD transit time & \multicolumn{3}{|c|}{$100 \mathrm{~ms}$} \\
\hline
\end{tabular}

Table 2: Results from TEM analysis for $\mathrm{Ag}, \mathrm{Au}, \mathrm{Cu}$

Figure 10: TEM pictures and corresponding size distributions of the produced nanoparticles from different materials in DBD ( $\left.g=2.45 \mathrm{~mm}, U_{p p}=13 \mathrm{kV}, V_{N 2}=0.5 \mathrm{~m} \mathrm{~s}^{-1}, Q_{N 2}=5 \mathrm{l} / \mathrm{min}\right)$

Higher amounts of materials are reported for silver, than for gold and then copper, as expected from the respective energy for melting required for vaporization and discussed in the last part.

\subsection{Growth of nanoparticles during the post-production transit between the filaments}

The effect of the number of filaments on particle growth during the transit in the gap, at constant energy per filament is depicted here. To do so, size distributions have been measured at different voltages with different number of similar filaments during a constant transit time, as well as with different transit times controlled by the flow-rate at constant voltage in the same DBD.

\subsubsection{Applied voltage}

Larger particles are observed at higher voltages in the Ag-DBD on the size distribution of Figure 11. The number of filaments during the transit time and the mean surface temperature increase with the voltage at constant energy per filament as depicted from Figure 6a (see §-3.1).

(a)

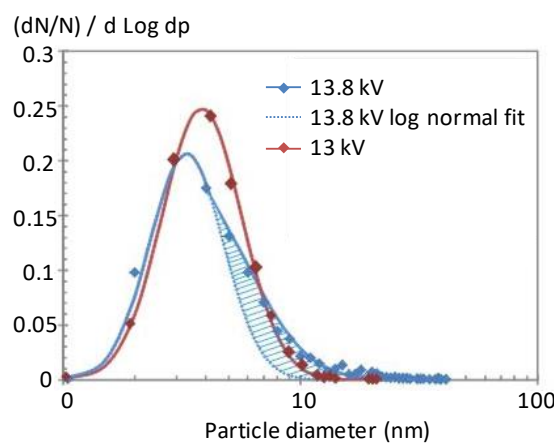

(b)

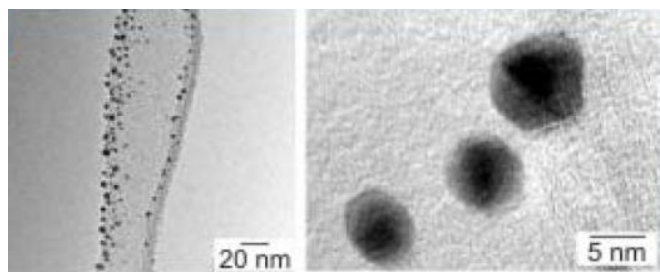

Figure 11: (a) Influence of the applied voltage on the particle size distribution $(g=2.45 \mathrm{~mm})$ and (b) TEM pictures of silver nanoparticles produced at $13 \mathrm{kV}$.

Indeed, at $13.8 \mathrm{kV}$, a shoulder appears on the log normal size distribution as well as a new larger mode from 10 to a few tens of nanometers. This new mode for a few spherical particles observed with more volatile silver electrode at high voltage, is not detailed here but discussed in the last section.

The shoulder is related to the agglomeration of nanoparticles produced by similar filaments whatever the voltage is, but more numerous at higher voltages. Despite the apparent reduction of the modal diameter, the count mean diameter increase from $3.83 \mathrm{~nm}$ at $13 \mathrm{kV}$ up to $4.1 \mathrm{~nm}$ at $13.8 \mathrm{kV}$, as well as the geometrical standard deviation from 1.4 to 1.53 . This is typical of coagulation of more concentrated nanoparticles and this was expected from the increase number of filaments during the transit, producing more local injections in the gas of nanoparticles from the vaporized surface. 


\subsubsection{Flow rate}

The mean particle size and the standard deviation decrease from 4.1 to $2.78 \mathrm{~nm}$ and from 1.44 to 1.34 , respectively, when increasing the gas flow rate from 2 to $10 \mathrm{lpm}$ (cf. Figure 12).

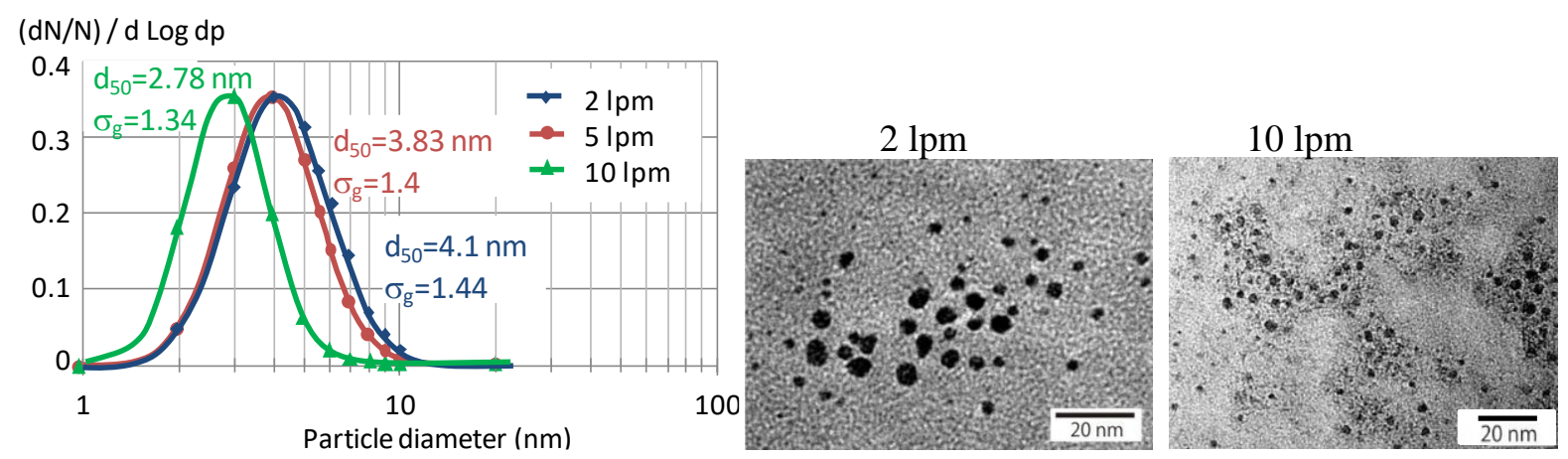

Figure 12: Influence of the flow rate on particle size distributions (Au-DBD, $g=2.45 \mathrm{~mm}, U_{p p}=13 \mathrm{kV}$ )

\begin{tabular}{lccc} 
Flowrate $(\mathbf{Q}$ in $\mathbf{l p m})$ & $\mathbf{2}$ & $\mathbf{5} \mathbf{~ p m} \leftarrow \mathbf{\mathbf { 0 . 5 }} \mathbf{~ m ~ s}^{-\mathbf{1}}$ & $\mathbf{1 0}$ \\
Transit time $(\mathbf{m s})$ & $\mathbf{2 0} \mathbf{~ m s}$ & $\mathbf{8} \mathbf{~ m s}$ & $\mathbf{4} \mathbf{~ m s}$ \\
\hline Count mean diameter $d_{50}(\mathrm{~nm})$ & 4.1 & 3.83 & 2.78 \\
\hline Geom. Standard dev. $\left(\sigma_{g}\right)$ & 1.44 & 1.4 & 1.34 \\
\hline Number of particles included in the size dist. & 1579 & 1506 & 1052
\end{tabular}

Table 3: Results from the analysis of TEM images in Au-DBD for different flow rates

To sum up, both the voltage and the flow rate affect the post-production agglomeration during the transit in the DBD, as expected for self-preserving size distribution of agglomerates in nucleation processes for higher concentration or longer agglomeration of nanoparticles (Buesser et al., 2009). Hence, after the local nucleation and agglomeration in each vapor jet, presented above in $\$-3.2$, the so-produced nanoparticles still grow during the post-production transit between the filaments. The first local agglomeration step can be limited at reduced energy per filament, while the second one also depends on both the number of filaments during the transit in the DBD and the transit time, as detailed in section 3.4.4. Indeed, in such lab-scale DBD, the final mean diameters can be controlled from 2 to $5 \mathrm{~nm}$.

\subsection{Discussion}

This section aims to confirm that in DBD, non-thermal plasma filaments trigger surface vaporization. Here, only the heating and evaporation of the metal surface is considered by analogy to models developed for lasers and sparks. Sputtering by ions, has been considered for more energetic streamers and sparks (Borra 2006) and detailed in Warrier (2004) and in Beilis (1995) for vacuum arcs, but can be neglected in atmospheric pressure DBD (Pitchord et al. 2006). The production of nanoparticles is then related to material properties and plasma parameters.

\subsubsection{Energy deposition by discharge filaments}

The electrical energy injected in the plasma filament is not entirely deposited on surfaces. The energy per filament is distributed over different processes: electron acceleration leading to avalanches and charge migration, then converted into chemical reactions, light emission and heating of both the gas and the surfaces (Boeuf, 1986). Moreover, the fraction of the energy per filament deposited in the spot probably varies with the gap and is not the same on both anode and cathode side of the filament.

With relatively low energies per filament in DBD (up to tens $\mu \mathrm{J}$ ) compared to laser and spark, the duration and the area of interaction with the surface $\left(<10 \mathrm{~ns}\right.$ and $d_{s p o t} \sim$ few $\left.\mu \mathrm{m}\right)$ lead to energy density $\left(E_{\text {per fil }} / S_{\text {spot }}\right)$ and energy flux (also referred as surface power density $=E_{\text {per fil }} /\left(S_{\text {spot. }} \cdot t_{\text {spot }}\right)$ ) up to $10^{6} \mathrm{~J} \mathrm{~m}^{-2}$ and $10^{14} \mathrm{~W} \mathrm{~m}^{-2}$, far above the one required for heating, melting and vaporization, detailed below. 


\subsubsection{Spot temperature and melting}

The melted area of the spot depends on the deposited heat flux, defined as a fraction of the total energy of the filament, minus radiative and heat conduction losses, as introduced by Llewellyn Jones (1950).

A large fraction of the power injected in the DBD is devoted to electrode heating (e.g. up to $50 \%$ in Jidenko et al., 2010). The mean surface temperature varies here from ambient to $130{ }^{\circ} \mathrm{C}$ at $70 \mathrm{kHz}$ in the lab-scale DBD. This macroscopic temperature does not only result from the heat flux in the spot, but includes other processes like surface reactions subsequent to the filament. Hence, the fraction of the total energy per filament related to the initial heat flux in the spot of filaments still has to be defined in DBD. However, while the plasma and the mean surface temperatures are far below the melting point of metals, the spots reach higher local temperatures since craters formation with melted edges is reported with Si and glass surfaces (Yeo et al. 2007 and Wang et al. 2010a and b). Besides, with such short energy injection on so small surfaces, the spot temperature may increase above the melting point, as already modeled in sparks by Gleizes et al. 2005. Hereafter, we refer to the total energy per filament rather than to an undefined heat flux in the spot, since the last one is far above the one required for heating, melting and vaporization.

\subsubsection{Vapor emission, transport and nucleation}

Vaporization of solid is usually modeled versus the deposited energy flux $\left(\mathrm{W} \mathrm{m}^{-2}\right)$ to account for dynamics of heat transfers in the electrode or versus the energy density $\left(\mathrm{J} \mathrm{m}^{-2}\right)$ to deal with the related production of vapors. Despite the short duration of the filament-surface interactions in the order of a few ns, heat conduction occurs in the volume of the material since the characteristic times of propagation in metals are shorter $\left(<10^{-10} \mathrm{~s}\right)$. Then, longer characteristic times for melting and vaporization have been calculated for sparks (e.g. from $1.08 \mu$ s at $10^{11} \mathrm{~W} . \mathrm{m}^{-2}$ down to $35 \mathrm{~ns}$ at $10^{12} \mathrm{~W} \mathrm{~m}^{-2}$ Rossignol et al. 2000). At atmospheric pressure, the subsequent adiabatic expansion induces vapor jets up to a fraction of millimeters from the spot within a few hundred ns with sparks (Smirnov 1993, Itina and Voloshko 2013) as well as with lasers (at $\sim 10^{9} \mathrm{~W} \cdot \mathrm{m}^{-2}$ in Farid et al 2014, in Chen et al 2006 and in Autrique et al. 2013). Hence, with energy densities above the threshold fluencies for metal vaporization and energy fluxes in the same order of magnitude as in lasers and sparks, surface vaporization of solids, vapor jet formation and expansion are also expected in non-thermal DBD.

In different models of surface vaporization by lasers and sparks, the amount of melted material is first related to the inverse of the energy required for melting $\left(\Delta H=\left(\int_{T_{0}}^{T_{\text {melting }}} C_{p} . d T+L_{\text {melting }}\right)\right.$, i.e. the sum of the energy to heat up the material to the melting point and of the melting enthalpy $L$ in $\mathrm{J} \mathrm{mol}^{-1}$, where $C_{p}$ is the heat capacitance in $\mathrm{J} \mathrm{K}^{-1} \mathrm{~mol}^{-1}$ ). Then, the vapor production per spot is calculated by integration of the vapor flux over the spot diameter and over the duration of existence of melted metal at the surface of the spot. The vapor flux $\left(\mathrm{mol} \mathrm{m}^{-2} \mathrm{~s}^{-1}\right.$ or $\left.\mathrm{kg} \mathrm{m}^{-2} \mathrm{~s}^{-1}\right)$ can be calculated with two approaches detailed in Lasagni 2004 and Murphy 2010 for sparks, versus the saturation vapor pressure or versus the vaporization enthalpy.

In the "energy flux" approach, the vapor flux is related to the heat flux $\left(\mathrm{J} \cdot \mathrm{m}^{-2} \cdot \mathrm{s}^{-1}\right)$ deposited by the plasma divided by the required energy for heating, melting and surface vaporization with $J_{v a p}=$ input heat flux / $\Delta H$ heating + melting + vaporization.

In the "vapor pressure" approach, the melted surface is defined by the input heat flux divided by the energy required for melting, with $J_{\text {vap }}=p_{\text {sat. }} \times\left(m_{M} / 2 \pi k_{B} T_{\text {melting }}\right)^{1 / 2}$ from Langmuir 1913, generally assumed to be at the melting temperature.

Finally, the saturation of the hot metal vapors triggers nucleation in each vapor plume, as depicted in models of fume formation in atmospheric pressure (in Tashiro et al. 2010 for welding arc in quasistationary vapor profile and in Wen et al. 2007 for expanding vapor plume around repetitive laser).

Before calculations discussed in the next section, surface vaporization has been first confirmed here in DBD by the size distributions depicted above. Such small primary particles $(<5 \mathrm{~nm})$ can only be produced by physical nucleation of hot vapors quenched by the carrier gas in the mobile front of expanding jets. It has been shown that in DBD as well, the local vapor flux from surfaces depends on both the energy per filament and the material properties in Figures 9 and 10 respectively.

The large excess of metal nanoparticles compare to alumina nanoparticles can be related to higher energy fluxes and temperatures in the metal spots than in the ones on alumina, as depicted in section 3.1. More vapors is thus produced from hotter metal spots confined on the same positions on the edges of the metal electrode, further intensified by the smaller enthalpy required for heating and melting and the higher saturation vapor pressures for metals than for $\mathrm{Al}_{2} \mathrm{O}_{3}$. 
Larger mean particle diameters are produced with more filaments during the transit in the gap, at higher voltages and/or lower flow rates. This can only arise from larger amount of material vaporized during the transit in the DBD (see Figures 11 and 12).

Therefore, the results presented above confirm that the solid material is vaporized by discharge filaments. Pure crystalline and amorphous nanoparticles $(<5 \mathrm{~nm})$ with the same composition as the solid target are formed by physical nucleation. Each discharge filament is a local and transient source of energy with local production of vapors and nanoparticles. DBD can thus be considered as a generator of nanoparticles locally produced from similar sources.

\subsubsection{Agglomeration in the DBD $\rightarrow$ controlled size distribution and morphology}

A fraction of the nanoparticles are coagulated into rather spherical agglomerates with sizes up to $10 \mathrm{~nm}$ made of a few nucleated particles (from 2 to $5 \mathrm{~nm}$ ). As depicted above, agglomeration occurs at the end of the vapor jet expansion and during the transit between subsequent filaments in the DBD when previously formed particles cross expanding jets of vapors and particles. The final particle size of agglomerates has been shown to increase with the energy per filament in section 3.2.2.1 and with both the number of filaments during the transit and the transit time in the DBD in section 3.3. Both the energy per filament and the number of filaments during the transit in the DBD control the vapor and nanoparticles fluxes in a unit gas volume during the transit. Neglecting the evolution of particle concentration as well as vapor and particle losses on the wall along the DBD, the nanoparticles flux divided by the flow rate is related to a mean particle concentration. The final particle size of agglomerates then increases with the mean particle concentration on the one hand and with the transit time on the other hand, both controlling the agglomeration.

This was expected since the requirements for ballistic agglomeration are largely fulfilled at the end of the vapor jet expansion as well as during the transit between subsequent filaments in the DBD, close to STP. Indeed, with nanoparticles smaller than the gas mean free path, collisions between particles occurs on ballistic trajectories and leads to compact agglomerates (Weber et al 1996). Hence, plasma filaments in DBD allow one to design the particle characteristics such as the size of particles below $5 \mathrm{~nm}$ and the morphology of spherical agglomerates while preventing dendritic agglomeration in DBD.

In principle, electrostatic coagulation could also contribute to agglomeration in the DBD. However, the small nucleated particles below $5 \mathrm{~nm}$ are only charged by diffusion and partial charging would only lead to a fraction of charged nanoparticles $(<10 \%)$. Hence, although electrostatic coagulation cannot be excluded, it is safe to say that this is not the main agglomeration mechanism.

At this point, it has to be mentioned that some larger spherical particles up to a few tens of $\mathrm{nm}$ are observed with the more volatile silver electrode, when higher amount of vapors are emitted from the surface during the transit in DBD. Indeed, they appear more numerous when the number of similar filaments during the transit in the DBD is increased for higher voltages and/or for longer transit times from 4 to $20 \mathrm{~ms}$. EDX analyses show that these larger spherical particles are made of silver. Hence, these larger spherical particles are not formed in the initial expanding vapor plume.
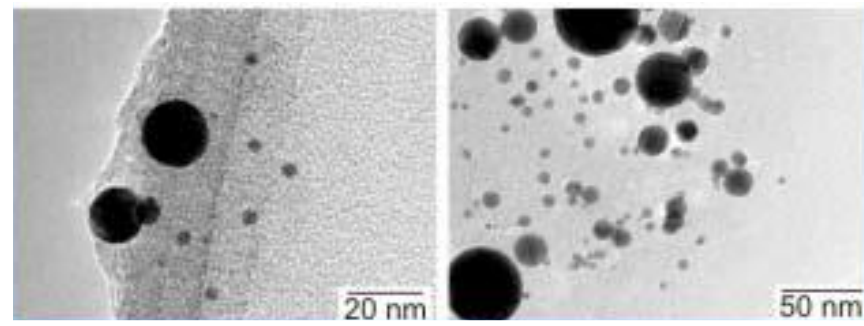

Figure 13: TEM pictures of silver nanoparticles (smaller primary nucleated nanoparticles up to $5 \mathrm{~nm}$ and agglomerates up to $20 \mathrm{~nm}$, as well as perfectly spherical particles up to a few tens of nanometers

These larger spherical particles are thus probably formed by heterogeneous nucleation on primary particles and/or resulting agglomerates, called coalescence (Teleki et al. 2008). Indeed, the sintering of melted agglomerates can be excluded since the cooling of expanding vapor jet leads to temperatures below the melting and sintering ones during the post-production transit in the DBD. 


\subsubsection{Production of nanoparticles versus material properties and plasma parameters}

\subsubsection{Evaluation of mass production rates of nanoparticles}

The number concentration of primary nanoparticles produced by the DBD is derived from the concentration of agglomerates measured by SMPS after 60 seconds in post-DBD and corrected for the detection efficiency of the CPC and for losses in and after the DBD, depicted in $\$ 2.2$ and appendix 2.

To do so, we used the work of Weber et al. 1996, describing the shape of agglomerates in the free molecular regime for ballistic and diffusion limited agglomeration. The number of primary particles per agglomerate with diameter $d_{50 \text {, agglom. }}$, is given by $N_{p p / a g g l o m}=A\left(d_{50, \text { agglom. }} / d_{p p}\right)^{D f}$, with $d_{p p}$ the primary particle diameter, a filling parameter $A=0.5$ and the fractal-like dimension $D_{f}=3$, for ballistic agglomeration. The total number of primary particles per unit volume is defined as the product of $N_{\text {pp/agglom }}$ time the number concentration of agglomerates. The mass production rate $\left(\mathrm{kg} \mathrm{s}^{-1}\right)$ is calculated as the product of the mass concentration of primary particle times the volume gas flow, then divided by the input power and the molar mass to define the production per unit energy $\left(\mathrm{mol} \mathrm{J}^{-1}\right)$.

\subsubsection{Production per unit energy $\left(\mathrm{mol} \mathrm{J}^{-1}\right)$ and energy yield (\%) versus the material properties}

The production per unit energy is compared versus material properties for gold, silver and copper to account for the molecular vapor flux rather than for the mass flux depending on the molecular weight. Thus, the production per unit energy (in mol $\mathrm{J}^{-1}$ rather than in $\mathrm{g} \mathrm{J}^{-1}$ ) is presented here versus the inverse latent heat of melting $\left(\mathrm{mol} \mathrm{J}^{-1}\right)$. As discussed in $\$ 3.4 .2$, the temperature of the metal spot submitted to successive filaments during the same half period, can be assumed to be close to the melting temperature. Therefore, the heating enthalpy up to the melting temperature is not taken into account here. This is done for different gap lengths controlling the energy per filament in Figure 14a. The number of filaments during the transit in the DBD was kept constant by lowering the voltage in smaller gap, as depicted in Table 1, implying higher power in larger gaps.
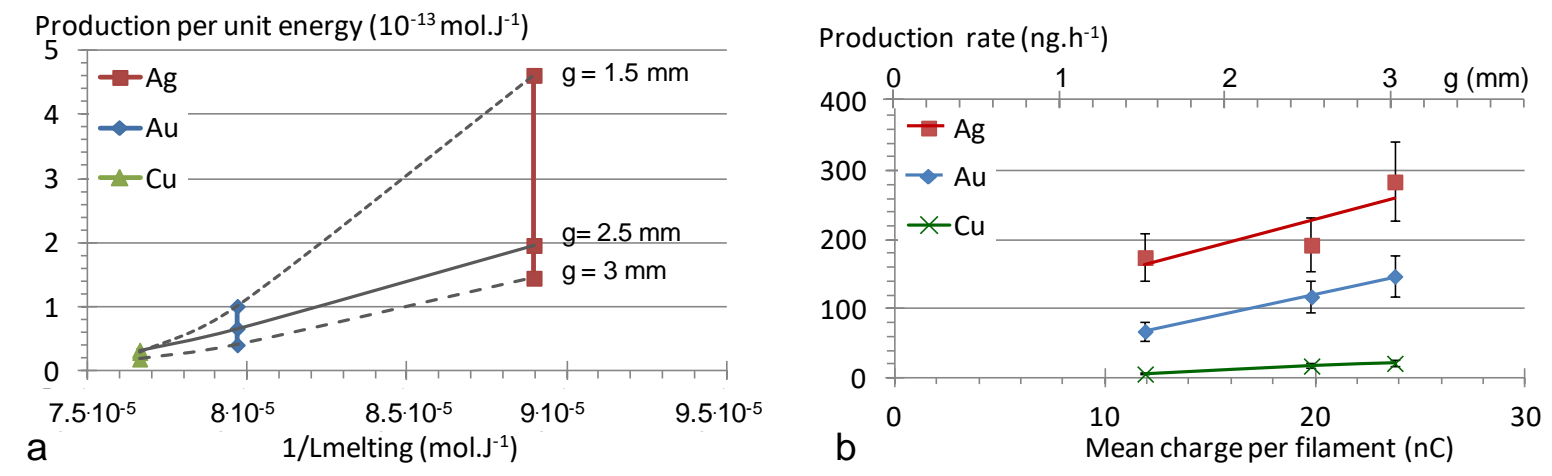

Figure 14: (a) Production per unit energy versus the inverse of melting enthalpy for different gap lengths and (b) Mass production rate versus the mean charge per filament in the sub-cm ${ }^{2}$ lab-scale DBD at $70 \mathrm{kHz}$

Despite rough assumptions neglecting the energy required for vaporization, the production per unit energy tends to be proportional to the inverse of the melting enthalpy, in Figure 14a for different gaps.

Hence, as a rule of thumb, the melting enthalpy can be used at first approximation to estimate the production rate of nanoparticles by DBD on different metals.

These results are coherent neither with the "energy flux" nor with "vapor pressure" approaches. However, attempts to correlate the production rate and the vapor flux with the "energy flux" and the "vapor pressure" approaches, all failed. Indeed, the vapor flux per spot is not evaluated properly since the melted surface is probably controlled by heat exchanges, neglected in both cases. At first, neither the energy density nor the flux in the spot is accurately defined as detailed in 3.4.1. Then, neither the area of the melted metal surface producing vapor nor the evolution of the temperature profile, nor the duration of existence of melted metal in the spot is defined as detailed in 3.4.2. Moreover, local recollection of vapors and nucleated nanoparticles in the DBD is not included to correct the production rates. Different spot diameters and heat exchanges are both expected for each metal and may be amplified with our different shapes of the edges of the electrodes. Hence, this relation still deserves to 
be confirmed with other metals and without edge effects, for the evaluation of the amount of vapor produced per spot, from such measurements of nano-particles.

Finally, Figure 14a also shows that the production per unit energy of nanoparticles production derived from post-DBD aerosol measurements, decreases in larger gaps with more energetic filaments. Since the production per filament has been shown to increase with the energy per filament in section 3.2.2.1, this implies that the nanoparticles production per filament derived from post-DBD aerosol measurements increases less than the energy per filament. Either the vapor production increases less than the energy per filament or more probably, the lost fraction of vapors and nanoparticles recollected increases with more energetic filament. Indeed, the local recollection of vapors and nanoparticles around the hot spot, from the vapor jet to colder surfaces between spots probably increases with the energy per filament. As a result, in these $70 \mathrm{kHz}$ lab-scale DBD with ms transit times, the energy yield (defined as the ratio of the energetic cost for vaporization from melting temperature of the amount of material produced per second on the input power) lies between $10^{-7}$ to $10^{-9} \%$. However, the production per unit energy and the related energy yield can be improved with other DBD configurations reducing vapor and aerosol recollection as well as heat losses in the electrode.

\subsubsection{Production rate versus plasma parameter}

At first approximation, neglecting vapor and nanoparticles losses, the mass production rate $\left(\mathrm{g} \mathrm{s}^{-1}\right)$ depends on the input power i.e. on the product of the number of filaments per second related to plasma parameters (voltage, gap, frequency and surface, as defined in section 3.1), times the production per filament. The production per filament i.e. the local vapor flux from surfaces depends on the energy per filament for any given material, as shown in section 3.2.2.1 and discussed in section 3.4.3.

Finally, to control the process, the nanoparticles production rate $\left(\mathrm{g} \mathrm{s}^{-1}\right)$ is related to an easily measured electrical characteristic of DBD. The mass production rate is plotted on Figure 14b versus the charge per filament for different materials at constant number of filaments per second, in the $70 \mathrm{kHz}$ lab-scale DBD. The mass production rates for all metals are correlated to the charge per pulse i.e. to the total transferred charge by all filaments during the transit in DBD. Hence, the slope corresponding to the mass of nanoparticles per unit charge $\left(\mathrm{g} \mathrm{C}^{-1}\right)$ is constant for each material in a given DBD, whereas the mass of nanoparticles per unit energy $\left(\mathrm{g} \mathrm{J}^{-1}\right)$ evolves with the total energy injected per filament. Indeed, the charge per filament is proportional to the maximum current of the pulse related to the temperature of the plasma filament and probably to the energy flux in the spot (Marode, 1999), controlling the local vapor flux.

\section{Conclusion}

In DBD, the initial local vapor fluxes from spots of plasma-surface interaction is reduced compared to the ones from laser and sparks. Indeed, mean diameters of isolated primary particles below $3 \mathrm{~nm}$ and agglomerates thereof below $5 \mathrm{~nm}$ are produced for ms transit times in lab-scale DBD, with upper diameters below 5 and $10 \mathrm{~nm}$, respectively. It has been shown that the energy deposited in the spot of filaments controls the local vapor flux leading to single digit nanoparticles by a purely physical transformation of bulk metals. Up to $50 \%$ of isolated unagglomerated amorphous and crystalline particles are so-formed by physical homogeneous nucleation in mobile fronts of expanding vapor jets. Hence, each filament can be considered as a local and transient source of energy with related pulsed local production of vapors and nanoparticles. Then, some rather spherical agglomerates are also formed by ballistic agglomeration at the end of the jet expansion and during the transit between subsequent filaments. The first agglomeration step can be limited at reduced energy per filament, while the second one depends on the transit time.

The final particle size of non-agglomerated primary particles increases with the energy per filament. While the final particle size of agglomerates evolves on the one hand with energy per filament and with the number of filaments during the transit in the DBD. Both control the vapor and nanoparticles fluxes in a unit gas volume during the transit, leading to a mean particle concentration when divided by the flow rate. The final particle size of agglomerates also evolves on the other hand with the transit time controlling the agglomeration.

The production per unit energy can be roughly related to the inverse of melting enthalpies of the metal electrodes. However, this relation deserves to be refined with other metals and without edge 
effects, to account for subsequent vaporization and nucleation on both cathode and anode sides of the filament.

The mass production rate $\left(\mathrm{g} \mathrm{s}^{-1}\right)$, neglecting vapor and nanoparticles losses, depend on the input power related to the product of the number of filaments per second times the energy controlling the production per filament, for any given material. Moderate production rates in these lab-scale DBD with ms transit times powered with a few Watt have been increased with larger DBD at $50 \mathrm{~W}$. However, as in other physical nucleation processes like laser and spark, increasing the input power leads to larger agglomerates. If this is suitable for the production of nanopowders with large geometric standard deviation, it cannot be used directly for nanomaterials production processes. Indeed, nanomaterials exhibit tunable size-dependent properties mainly below $30 \mathrm{~nm}$, which implies to control the enlargement of the size distribution by coagulation. Hence, the main advantage of DBD is to avoid expensive postprocessing. In fact, to reach similar single digit metal nanoparticles with very high added value for nanotechnologies directly at atmospheric pressure, other nucleation processes such as spark, laser and flames require size selection and/or thermal sintering of agglomerates. As a consequence, this one step process still is interesting for industrial applications despite the low energy yields $\left(<10^{-6} \%\right)$ of these lab-scale DBD. This is especially true since great improvements are expected with other DBD configurations reducing vapor and nanoparticles recollection as well as heat losses in the electrode.

A new application of DBD is highlighted as gas phase process for the production of tailored metal particles with tunable size. This non-thermal plasma process presents great potentialities for nanotechnologies since compact, inexpensive and simple DBD is performed at atmospheric pressure and can be used to reach size-dependant properties of nano-materials, without any gaseous precursor nor solvent. Indeed, agglomeration has been successfully limited by short transit times of a few milliseconds in DBD with "low" energy plasma filaments (up to tens of $\mu \mathrm{J}$ ) and can still be optimized to produce only single digit unagglomerated metal nanoparticles. Indeed, with more homogeneous discharge filament properties, without edge effects, such as those described in the asymmetric lab-scale planar DBD, even less dispersed size distributions of metal nanoparticles are expected.

Finally, it has to be underlined that this nanoparticles production process by DBD has been proved to be versatile. Indeed, single digit nanometer sized, carbon, polymer, metal oxides and silicon nanoparticles have also been produced in this lab-scale DBD.

\section{References}

Altgeld H., Schnettler \& Stehmeier (1980) Spark discharge particle generator for laser Doppler anemometry J. Phys. E: Sci instrum, Vol 13 pp 437-441

Alonso M, Kousaka Y \& Hashimoto N (1997). Penetration of nanometer-sized aerosol particles through wire screen and laminar flow tube Aerosol Science and Technology 27, 471-480

Autrique D, Clair G., L'Hermite D., Alexiades V., Bogaerts A., \& Rethfeld B. (2013) The role of mass removal mechanisms in the onset of ns-laser induced plasma formation, Journal of Applied Physics 114, 023301; doi: $10.1063 / 1.4812577$

Bau S., Witchger O., Gensdarmes F., Thomas D. \& Borra J-P., (2010). Properties of airborne nanoparticles produced by a commercial spark-discharge generator,.J. Nanopart. Research 12, 1989.

Belmonte T., Arnoult G, Henrion G \& Gries T (2011). Nanoscience with non-equilibrium plasmas at atmospheric pressure, J. Phys. D: Appl. Phys. 44363001.

Beilis,I. Handbook of vacuum arc science and technology, ed Boxman \& al Noyes publication (1995), p209-282, Boeuf, JP \& Kunhardt, EE (1986) Energy balance in a nonequilibrium weakly ionized nitrogen discharge J. Appl. Phys., Vol: 60-3 pp 915-923, doi: 10.1063/1.337332

Borra J-P. (2006). Nucleation and aerosol processing in atmospheric pressure electrical discharges: powders production, coatings and filtration J. Phys. D: Appl. Phys. 39 R19-R54.

Borra J-P. (2008). Charging of aerosol and nucleation in atmospheric pressure electrical discharges Plasma Phys. Control Fusion 50, 124036

Borra JP, Bourgeois E. \& Jidenko N. (2009). Atmospheric pressure plasmas for aerosols processes in materials and environment Eur. Phys. J. Appl. Phys., Vol: 47-2 22804.

Borra J-P, Jidenko N, Dutouquet C, Aguerre O., Hou J. \& Weber A., (2011). Nano-droplet ejection and nucleation of materials submitted to non-thermal plasma filaments Eur. Phys. J. Appl. Phys., 56, 1286-0042, 24019 (7 p) from "18th Int. Colloq. Plasma Processes.

Bourgeois E., Jidenko N. \& Borra J.P. (2010) Nucléation et croissance de nanoparticules formées par décharge à barrières diélectriques, $25^{\text {ème }}$ Congrès Français des Aérosols, 13-14 janvier, Paris, France.

Buesser B., Heine M.C. \& Pratsinis S.E., (2009) Coagulation of highly concentrated aerosols J. Aerosol Science 40, pp $89-100$ 
Byeon J.H., Park J.H., \& Hwang J. (2008). Spark generation of monometallic and bimetallic aerosol nanoparticles, JAS, Volume 39, Issue 10, 888-896.

Chen Z, Bleiner D \& Bogaerts A (2006) Effect of ambient pressure on laser ablation and plume expansion dynamics: A numerical simulation, Journal of Applied Physics ,99, 063304; doi: 10.1063/1.2182078

Dewalle, P., Vendel, J., Weulersse, J.M., Herve, P., \& Decobert, G. (2011). Influence of Carrier Gas Flow Rate, Laser Repetition Rate, and Fluence on the Size Distribution and Number of Nanoparticles Generated Per Laser Shot During Paint Laser Ablation. Aerosol Science and Technology, 45, 1429-1440.

Eliasson B \& Kogelschatz U (1991). Modeling and applications of silent discharge plasmas IEEE Transactions on Plasma Science 19-2, 309-323.

Farid N., Harilal S. S., Ding H. \& Hassanein A., Emission features and expansion dynamics of nanosecond laser ablation plumes at different ambient pressures Journal of Applied Physics 115, 033107 (2014); doi: $10.1063 / 1.4862167$

Feng J., Maisser A., Pfeiffer T., Biskos G. \& Schmidt-Ott A. (2013). Size Controlled Synthesis of Spherical Nanoparticles by Spark Discharge, electronic proceedings of the EAC, Prague, Czech Republic, $1^{\text {st }}-6^{\text {th }}$ Sept. 2013, cf. http://eac2013.cz/EAC abstracta/Aerosol-based Nanotechnology/Feng-Jicheng_Aerosolbased_Nanotechnology_2013032-165413_1966751918.pdf.

Gamaly G.E. (2011) The physics of ultra-short laser interaction with solids at non-relativistic intensities, Physics Reports 508, 91-243

Gibalov V I \& Pietsch G J (2000). The development of dielectric barrier discharges in gas gaps and on surfaces $J$. Phys. D: Appl. Phys 33 2618-36.

Gleizes A, Gonzalez J J \& Freton P (2005). Thermal plasma modelling J. Phys. D: Appl. Phys. 38, R153-R183

Gormley P G \& Kennedy M (1949) Diffusion from a stream following through a cylindrical tube. Proceedings of Royal Irish Academy 52 163-169.

Hamdan, A., Noël C., Ghanbaja J., Migot-Choux S. \& Belmonte T. (2013) Synthesis of platinum embedded in amorphous carbon by micro-gap discharge in heptanes, Materials Chem and Phys, 142-1, 199-206

Han K., Kim W., Yu J., Lee J., Lee H., Woo C. G. \& Choi M. (2012). Study of Pin-to-Plate Type Spark Discharge Generator for Producing Unagglomerate Nanoaerosols, J. Aerosol Science, 52, 80-88.

Hinds W.C., Aerosol Technology, Properties, Behaviour, and Measurement of Airborne Particles 2nd edn (Wiley, New York, 1999).

Housiadas C \& Drossinos Y (2005). Thermophoretic Deposition in Tube Flow Aerosol Science and Technology 39 304-318.

Horvath H., \& Gangl M. (2003). A low-voltage spark generator for production of carbon particles”, J. Aerosol Sci, 34, 1581-1588.

ItinaT.E. \& Voloshko A. (2013). Nanoparticle formation by laser ablation in air and by spark discharges at atmospheric pressure, Appl. Phys B, published online, doi 10.1007//s00340-013-5490-6

Jidenko N \& Borra JP (2005). Kinematics of charged nanometric particles in silent discharge J. Phys. D: Appl. Phys. 38, 617-620.

Jidenko N. \& Borra J-P. (2006). Electrical characterization of microdischarges produced in dielectric barrier discharge in dry air at atmospheric pressure J. Phys. D: Appl. Phys. 39, 281-293.

Jidenko N, Bourgeois E. \& Borra JP (2010). Temperature profiles in filamentary dielectric barrier discharges at atmospheric pressure J. Phys. D: Appl. Phys. 43295203.

Kasper G (1980). Electrostatic dispersion of homopolar charged Aerosols Journal of Colloid and Interface Science 81-1, 32-40.

Kodas T.T. \& Hampden-Smith M., Aerosol Processing of Materials (New York: Wiley-VCH) (1999).

Langmuir I. (1913). the vapor Pressure of Metallic Tungsten, Phys. Rev., 2, 329-342.

Lasagni A., Soldera F. \& Mücklich F., (2004). Quantitative investigation of material erosion caused by highpressure discharges in air and nitrogen, International Journal of Materials Research 95-2, 102-108.

Llewellyn Jones. F. (1950) Electrode erosion by spark discharges, British J Appl, Phys. 1, 60-65

Marode E, Djermoune D, Dessante P, Deniset C, Ségur P, Bastien F, Bourdon A \& Laux C (2009). Physics and applications of atmospheric non-thermal air plasma with reference to environment, Plasma Phys. Control. Fusion 51124002.

Massines M. Sarra-Bournet C., Fanelli F, Naudé N., \& Gherardi N., (2012). Atmospheric pressure Low Temperature Direct Plasma Technology : Status, Challenges for thin film Deposition, Plasma Processes and Polymers, Vol. 9, Issue: 11-12, 1041-1073.

Murphy A.B. (2010). The effect of metal vapour in arc welding, J. Phys. D: Appl. Phys. 43, 434001. doi:10.1088/0022-3727/43/43/434001

Park K.T, Massoud M.F. \& Hwang J. (2014). Anti-agglomeration of spark discharge-generated aerosols via unipolar air ions, accepted in JA.S, 67, 144-156.

Petit M., Jidenko N. \& Borra JP (2002). Electrical characterization of gas discharges using a numerical treatment. Application to DBD, Review of scientific instruments, Vol. 73, $\mathbf{N}^{\circ} \mathbf{7}, 2705-2712$.

Pitchford LC, Wang J, Piscitelli D \& Boeuf JP (2006) Ion and neutral energy distributions to the MgO surface and sputtering rates in plasma display panel cells, IEEE Trans. on Plasma Science 34 -2 pp 351-359, Part: 2 ,doi: 10.1109/TPS.2006.872426 
Pratsinis S.E. (2008). Distinguishing between aggregates and agglomerates of flame-made TiO2 by high pressure dispersion, Powder Technol. 181, 292-300.

Rossignol J., Abbaoui M. \& Clain S. (2000). Numerical modelling of thermal ablation phenomena due to cathodic spot, J Phys D: Appl Phys, 33-16, 2079-2086.

Rudyak V Ya, Dubtsov S N, \& Baklanov A M (2009). Measurements of the temperature dependent diffusion coefficient of nanoparticles in the range of 295-600 K at atmospheric pressure J. Aerosol Sci., 40, 833-843.

Ramamurthi M \& Hopke P K (1989). On improving the validity of wire screen unattached fraction radon daughter measurements Health Physics, 56, 189-194.

Samukawa S., Hori M., Rauf S., Tachibana K., Bruggeman P., Kroesen G, Whitehead J.C., MurphyA.B., Gutsol AF, Starikovskaia S., Kortshagen U., Bœuf J.-P., Sommerer T. J., Kushner M. J, Czarnetzki U \& MasonN (2012). The 2012 Plasma Roadmap, J. Phys. D: Appl. Phys. 45, 253001.

Schmid G., Nanoparticles (2011): From theory to applications, John Wiley \& Sons

Smirnov B. M. (1993). Clusters in expanding Plasma, Plasma Chem. and Plasma Processing, 13-4, 673-684

Sublemontier O., Kintz H. \& Lacour F. (2011). Synthesis and on-line size Control of Silicon Quantum Dots, Kona Powder and Particle Journal, 29, 236-250.

Tashiro S, Zeniya T, Yamamoto K, Tanaka M, Nakata K, Murphy A.B,Yamamoto E, Yamazaki K \& Suzuki K (2010) Numerical analysis of fume formation mechanism in arc welding J. Phys. D: Appl. Phys. 43434012 doi:10.1088/0022-3727/43/43/434012

Teleki, A., Wengeler R., Wengeler L., Nirschl H., \& Pratsinis S.E., (2008). Distinguishing between aggregates and agglomerates of flame-made TiO2 by high pressure dispersion, Powder Technol. 181, 292-300.

Vollath D. \& Szabó V. (2006). The Microwave plasma process - a versatile process to synthesize nanoparticulate materials Journal of Nanoparticle Research, 8, 417-428.

Weber A.P., Baltensperger U., Gäggeler H.W. \& Schmidt-Ott A. (1996). In situ characterization and structure modification of agglomerated aerosol particles, J. Aerosol Sci, 27-6, 915-929.

Wang C., Zhang G. \& He X. (2010a). Effect of DBD on semiconductor Si electrode surface, Applied Surface Science 256 6047-6052 ; doi:10.1016/j.apsusc.2010.03.117

Wang C., Zhang G., Wang X. \& He X.(2010b) The effect of air plasma on barrier dielectric surface in DBD, Applied Surface Science 257 1698-1702 ; doi:10.1016/j.apsusc.2010.08.125

Warrier M, Schneider R \& Bonnin X (2004) Subroutines for some plasma surface interaction processes: physical sputtering, chemical erosion, radiation enhanced sublimation, backscattering and thermal evaporation. Computer Physics Communications 160 46-68, doi:10.1016/j.cpc.2004.02.011

Wen S-B., Mao X., Greif R. \& Russo R.E. (2007) Experimental and theoretical studies of particle generation after laser ablation of copper with a background gas at atmospheric pressure J. Appl. Phys. 101, 123105 doi: $10.1063 / 1.2748635$

Yeo S H, Kurnia W \& Tan P C (2007) Electro-thermal modelling of anode and cathode in micro-EDM, J. Phys. D: Appl. Phys. 40, 2513-2521, doi:10.1088/0022-3727/40/8/015 


\section{APPENDIX 1: ELECTRICAL CHARACTERIZATION of DBD}

A short overview of critical points for the electrical characterization of discharge filaments induced in DBD are framed. For each functioning condition, applied voltage, input power and individual current pulse characteristics $\left(\mathrm{I}_{0}, \mathrm{Q}, \Delta \mathrm{t}\right)$ have been measured.

Figure 15 shows the setup used to perform voltage and current measurements as well as discharge power calculations. Coaxial cable and $50 \mathrm{ohm}$ resistors prevent from electrical noise, current pulse distortion and echo.

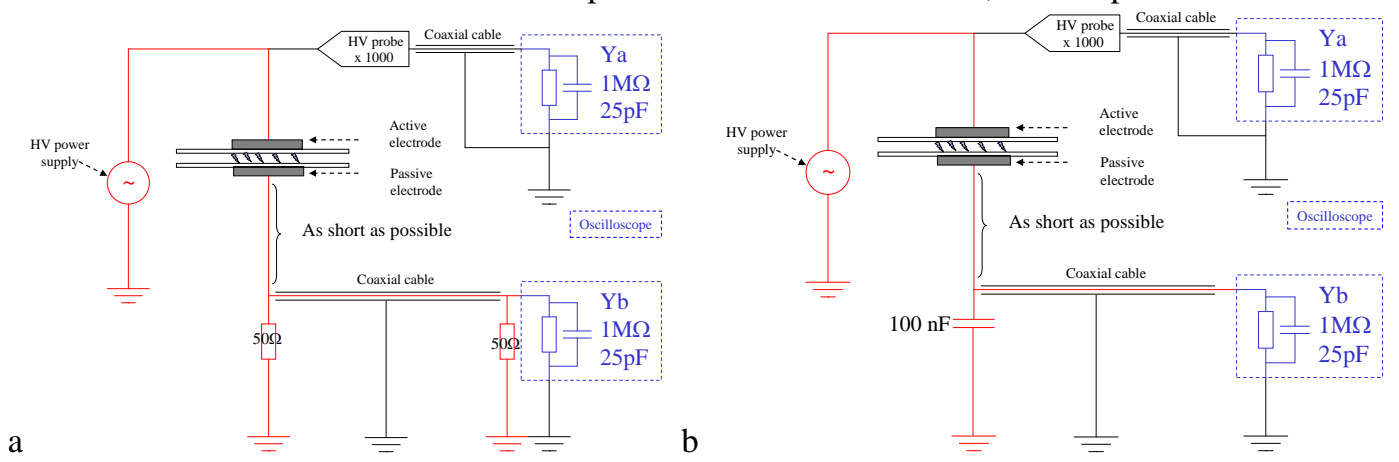

Figure 15: Setup (a) for current and voltage measurements and (b) for power measurements by Lissajou's method

The measured current depicted on Figure 5, has to be corrected by the parameter $\alpha$, because of the attenuation of the current amplitude due to the presence of dielectric materials. The correction parameter for current amplitude $(\alpha)$ has to be calculated and evaluated (from the first lightning voltage, $V_{t h}$ ) for each DBD reactor.

Relation between charge displacements in the gap and the measured current in a DBD

The real discharge current $\left(\mathrm{i}_{\mathrm{dis}}\right)$ can be evaluated by: ${ }_{i_{d i s}(t)=\alpha \cdot i_{\text {ind }}}=\left(1+\frac{C_{g}}{C_{d}}\right) \cdot\left(i_{m}(t)-C \frac{d u(t)}{d t}\right)$

where $\mathrm{C}, \mathrm{C}_{\mathrm{d}}, \mathrm{C}_{\mathrm{g}}$ the capacitances of the cell, of the dielectric materials and of the gap,

$\mathrm{i}_{\mathrm{m}}$ and $\mathrm{i}_{\text {ind }}$ are respectively the measured current and the current in the external circuit induced by the displacements of charge in the gap, and $\mathrm{u}$ is the applied voltage.

The parameter $\alpha$ can be calculated from measurements: $\alpha=\frac{V_{\text {first lightning }}}{V_{t}}$

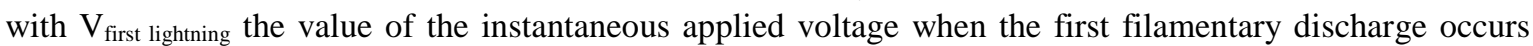
when the dielectric surfaces are not polarized (acquired with a single sequence when the dielectric surfaces are depolarized after a few days without functioning) and $\mathrm{V}_{\mathrm{t}}$ the threshold voltage of self sustained discharge. For further explanation see Jidenko and Borra (2006).

Then, the following electrical characteristics of pulses can be defined from the corrected current for a $1 \mathrm{~mm}$ gap.

- Electrical charge per pulse $Q_{\text {pulse }}$ (about nC) measured by integrating the instantaneous discharge current (without the capacitive current) during a pulse. $\left(\mathrm{Q}_{/ \text {pulse }}\right.$ is proportional to $d . \varepsilon_{r} / e$, with $d$ the gap length, $e$ the thickness and $\varepsilon_{r}$ the relative permittivity of dielectric material.

- Maximum current pulse $\left(I_{0} \sim 20 \mathrm{~mA}\right)$

- Duration of the pulse ( $\Delta t$ about 20 to $100 \mathrm{~ns}$ in air and nitrogen)

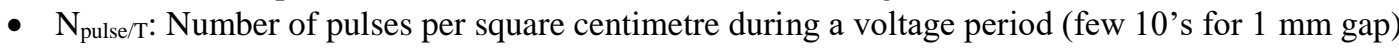

- Energy per pulse $\left(E_{\text {/pulse }}\right.$ in $\left.\mathrm{J}\right)$

Two methods are used for the evaluation of the energy per pulse:

- The real energy per pulse is $\int_{\text {(duration } \mathrm{f} \text { the pulse) }} i_{\text {dis. }} . v_{\text {gap }} d t$. Unfortunately the $\mathrm{v}_{\text {gap }}$ (voltage in the gap on the axis of the discharge filament) cannot be measured in a DBD. A rough estimation consists in assuming that the voltage is nearly constant equal to the threshold voltage of self-sustained discharge $\left(V_{t h} \sim 10.5 \mathrm{kV}\right.$ for $2.5 \mathrm{~mm}$ in $\left.\mathrm{N}_{2}\right)$. Thus, the energy per pulse is the product of the charge per pulse by the threshold voltage. $E n_{\text {/pulse }} \sim Q_{\text {/pulse }} . V_{t}$

- Assuming that all filament are identical, the mean energy per pulse can also be estimated by the ratio of the energy per period (input power divided by the frequency) by the number of pulse per period (En/pulse $\sim E n_{T} / N_{\text {pulse/T }}$ ).

The input power can be calculated either by $u i$ product integration over an integer number of periods, as detailed on Figure 15.a $\left(P=1 / n T \int_{(n T)} u(t) i(t) d t\right)$, or by the Lissajou's method, depicted on Figure 15.b. Here, the 50 ohm resistor is replaced by a capacitance. The input power $\left(P=F\right.$. $u d q$, with $q=C_{m} . v, C_{m}$ the capacitance and $v$ the voltage across the capacitance) is the area of the parallelogram, which represents the input energy per period $\left(E n_{T}\right.$ in J) times the frequency.

The number of filaments per period or per second is measured at low voltage when the number of filaments per period is small so that most of filaments start at different times. At higher voltages, a great fraction of current pulses related to filaments are superimposed. In that case, the number of filaments is calculated as the ratio of the energy per period or of the input power (derived from Lissajou's figures) on the energy per pulse calculated as the product of the charge per pulse by the threshold voltage. En/pulse $\sim Q_{/ p u l s e} . V_{t}$ 


\section{APPENDIX 2: LOSSES of NANOPARTICLES}

\section{Post DBD losses}

Thermophoresis : In DBD, the energy deposited on surfaces by filament heats the electrode as well as the dielectric material, which then heat the gas flowing between in the gap. Then, losses of particles by thermophoresis may occur from the gas towards colder surfaces of post-discharge tubes. An evaluation of post-discharge losses by thermophoresis has been performed (Housiadas C. and Drossinos Y 2005). Penetrations higher than $50 \%$ have been calculated in the worst conditions for $2 \mathrm{~nm}$ particles at $\mathrm{T}_{\text {gas }} \sim 80^{\circ} \mathrm{C}$, encountered in post-DBD (see Figure 5b). Hence, these losses can be neglected.

Diffusion have been estimated using Gormley et Kennedy equations (Gormley and Kennedy, 1949), which have been validated for particles larger than $2 \mathrm{~nm}$, for laminar flow (Alonso et al., 1997). This formula takes into account the effect of the gas temperature after the DBD, measured from 20 et $200{ }^{\circ} \mathrm{C}$ on the diffusion coefficient of particles (Rudyak et al. 2009). For smaller particles than $2 \mathrm{~nm}$, the diffusion coefficient is multiplied by a correction factor to ensure the continuity with the diffusion coefficient obtained from the gas kinetic theory (Ramamurthi and Hopke, 1989).
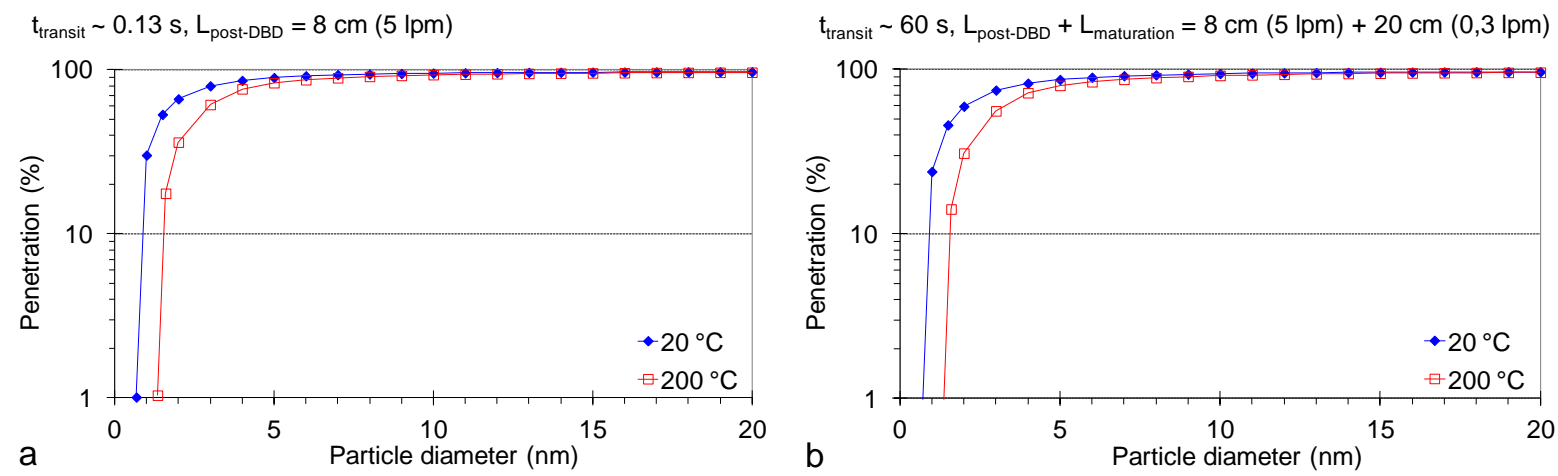

Figure 16: Aerosol Penetration versus particle diameter at 20 and $200^{\circ} \mathrm{C}$ before measurements. (a) for $0.13 \mathrm{~s}$ in the DBD and in post-DBD before collection on TEM grids and (b) for 60s in the post-DBD coagulation volume $\left(300 \mathrm{~cm}^{3}\right.$ at $\left.0.3 \mathrm{lpm}\right)$ before SMPS measurements.

These calculations show that losses by diffusion are lower than $50 \%$ for particles larger than 1.5 and $2.5 \mathrm{~nm}$ at $20^{\circ} \mathrm{C}$ and $200^{\circ} \mathrm{C}$ respectively for 60 s in post-DBD (see Figure 16). Then, in this work at $\mathrm{T}_{\text {gas }} \sim 80{ }^{\circ} \mathrm{C}$, losses by diffusion are around $55 \%$ at $2 \mathrm{~nm}$ for $60 \mathrm{~s}$ in post-DBD (see Figure 16b) and around $45 \%$ for $0.13 \mathrm{sec}$ in the labscale DBD without the post-DBD coagulation volume (see Figure 16a). For the more numerous particles between 2 to $5 \mathrm{~nm}$ from the lab-scale DBD, lower losses have been included for correction of the measured concentration, required for the calculation of the mass production rates.

Besides, the effect of the gas temperature from 20 to $200{ }^{\circ} \mathrm{C}$ is negligible for diffusion losses above 2 nm. However, losses by diffusion at $1 \mathrm{~nm}$ increase up to $70 \%$ for short post-DBD on Figure 16a and up to $80 \%$ for 60 sec in the coagulation volume in post-DBD (see Figure 17b).

Coulombian losses by electrostatic repulsion have also been considered since particles may be charged by diffusion during their transit in bipolar ions in as well as after the DBD (Bourgeois et al. 2010), for ion densities higher than $10^{6-7} \mathrm{~cm}^{-3}$, as described in Kasper, 1980. However, for particles smaller than $10 \mathrm{~nm}$, only a small fraction of particles are charged at the Boltzmann equilibrium (0.6\% at $10 \mathrm{~nm}$, in Hinds, 1982). Losses by electrocollection of charged particle after the DBD can thus be neglected, as confirmed by tests with or without an electrostatic precipitator before the measurements.

As a result, it is first shown that post-DBD losses by thermophoresis and electrostatic repulsion can be neglected while diffusion losses have to be taken into consideration for particles smaller than $2 \mathrm{~nm}$.

\section{Losses in the lab-scale DBD}

With transit times in the order of ms, diffusion and electrostatic losses of nanoparticles can be neglected in the DBD. Electro-collection has been proved to be inefficient for such small particles in DBD at $60 \mathrm{kHz}$ (Jidenko et al, 2005). Indeed, such small nucleated particles below $5 \mathrm{~nm}$ are only charged by diffusion and partial charging would only lead to a fraction of charged nucleated nanoparticles $(<10 \%)$.

Hence, at first approximation, initial losses of vapors and nanoparticles are neglected in the DBD despite probable thermal diffusion and thermophoresis inducing local recollection of vapors around the hot spot, from the expanding vapor jet to the colder surfaces between spots. 